University of Rhode Island

DigitalCommons@URI

Open Access Master's Theses

2017

\title{
A High-Resolution Reconstruction of Late-Holocene Relative Sea Level in Rhode Island, USA
}

Rachel B. Stearns

University of Rhode Island, rachstearns@gmail.com

Follow this and additional works at: https://digitalcommons.uri.edu/theses

\section{Recommended Citation}

Stearns, Rachel B., "A High-Resolution Reconstruction of Late-Holocene Relative Sea Level in Rhode Island, USA" (2017). Open Access Master's Theses. Paper 1057.

https://digitalcommons.uri.edu/theses/1057

This Thesis is brought to you for free and open access by DigitalCommons@URI. It has been accepted for inclusion in Open Access Master's Theses by an authorized administrator of DigitalCommons@URI. For more information, please contact digitalcommons-group@uri.edu. 
A HIGH-RESOLUTION RECONSTRUCTION OF LATE-

HOLOCENE RELATIVE SEA LEVEL IN RHODE ISLAND, USA

BY

RACHEL B. STEARNS

A THESIS SUBMITTED IN PARTIAL FULFILLMENT OF THE

REQUIREMENTS FOR THE DEGREE OF

MASTER OF SCIENCE

IN

BIOLOGICAL AND ENVIRONMENTAL SCIENCE

UNIVERSITY OF RHODE ISLAND

2017 


\section{MASTER OF SCIENCE IN BIOLOGICAL AND ENVIRONMENTAL SCIENCE $\mathrm{OF}$}

\section{RACHEL B. STEARNS}

\section{APPROVED:}

Thesis Committee:

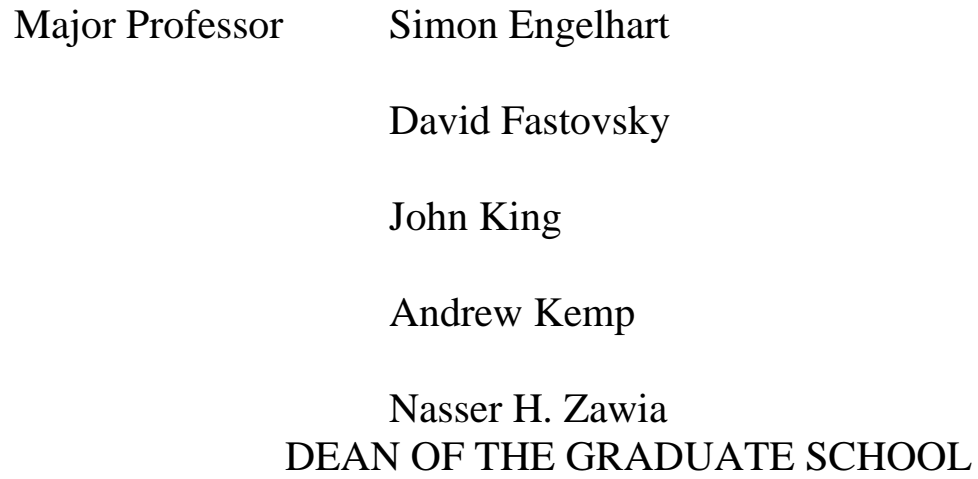




\begin{abstract}
To investigate spatial and temporal variability of relative sea-level (RSL) changes in southern New England, USA, we reconstructed 3,300 years of RSL change in lower Narragansett Bay, Rhode Island. We applied a regional-scale, foraminiferal-based Bayesian transfer function to foraminiferal assemblages contained within a $\sim 3.4 \mathrm{~m}$ saltmarsh peat sequence recovered at Fox Hill Marsh. To develop the chronology, we obtained 30 accelerator mass spectrometry (AMS) radiocarbon dates from plant macrofossils and identified historical chronological markers of known age using ${ }^{137} \mathrm{Cs}$, heavy metals, and lead isotope ratios. We combined our geologic reconstruction with local tide gauge measurements from Newport, Rhode Island (1931-2016 CE) and used an Errors-in-Variables Integrated Gaussian Process (EIV-IGP) model to estimate past rates and positions of RSL. Our reconstruction shows RSL rose from $-3.9 \mathrm{~m}$ at $\sim 1250$ BCE reaching $0 \mathrm{~m}$ at present $(2014 \mathrm{CE})$ and identifies multiple oscillations of accelerating and decelerating RSL superimposed on this overall rising trend. Sea-level change was also evaluated by removing a linear glacial isostatic adjustment (GIA) contribution of 0.9 $\mathrm{mm} / \mathrm{yr}$ from our record that we then compared against other detrended sea-level reconstructions in the region to identify climate-driven sea-level trends. This analysis demonstrates that sea level deviated multiple times from stability during the $\sim 3,300$-year record, and included oscillations that have been identified at other sites as due to the Medieval Climate Anomaly and Little Ice Age. Further, sea-level was rising at 2.74 \pm 0.79 $\mathrm{mm} / \mathrm{yr}$ in $2014 \mathrm{CE}$, the fastest century-scale trend in the $\sim 3,300$-year record. Apart from the onset of modern rates of rise, the timing of the departures from stability varies from other southern New England and mid-Atlantic records in Connecticut and New York,
\end{abstract}


respectively, with additional oscillations identified in Rhode Island that are not present in the Connecticut record. After considering multiple physical and RSL methodological explanations, we conclude that this may be due to the increased density of radiocarbon dates in our chronology or the resolution of paleomarsh elevation (PME) estimates compared to other RSL reconstructions in the region. 


\section{ACKNOWLEDGMENTS}

I would like to thank my graduate advisor, Dr. Simon Engelhart, for all the advice, support, opportunities to do amazing things, and for constantly putting up with my bad jokes and poor beer choices. I have the utmost respect for you and it has been a pleasure learning from you. I would also like to thank Dr. Andrew Kemp, who pushed me to be a better writer by consistently offering helpful advice and comments while writing this thesis. I would like to thank my committee members: Dr. David Fastovsky, for always lending a kind word and Dr. John King, for coming on board so last minute. I would also like to thank Dr. Brian Savage, who always took the time to listen and offer kind words of encouragement. This work was made possible by the National Fish and Wildlife Foundation, Rhode Island Sea Grant, and the Cushman Foundation of Foraminiferal Research. I thank the Earthwatch organization for funding fieldwork and all the hardworking teens who enthusiastically helped in the field. Thank you to Dr. Timothy Shaw and Jennifer Walker for helping conduct fieldwork. I would like to thank J Padgett, Matthew Gerlach, Byron Halavik, Greta Janigian, Dan Russell, Caroline Amelse, Nicole Brennen, Michaela Cashman, Abigail Johnson, and Lauren Josephs, who either helped in the field and the lab or who just helped me get through the day. To Mom and Dad, who I could not have done this without, thank you a million times over. 


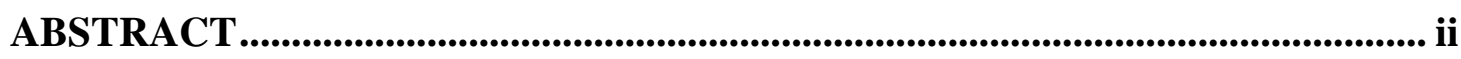

ACKNOWLEDGMENTS .......................................................................................... iv

TABLE OF CONTENTS .....................................................................................................

LIST OF TABLES ................................................................................................................. vi

LIST OF FIGURES ........................................................................................................... vii

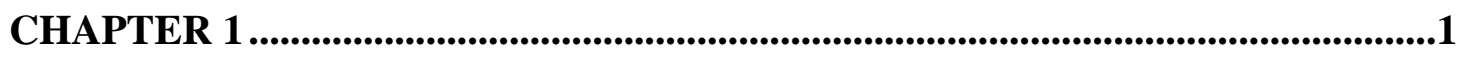

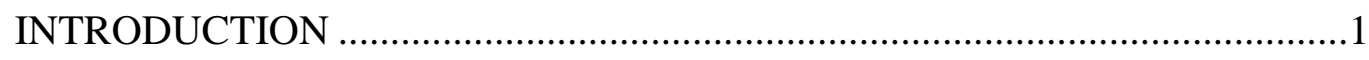

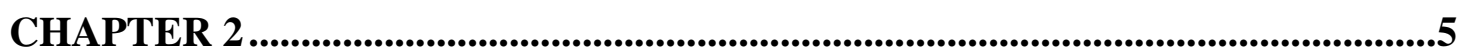

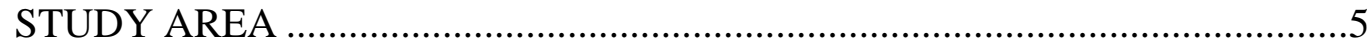

CHAPTER 3 ..............................................................................................................8

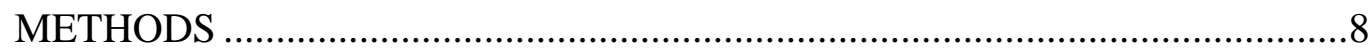

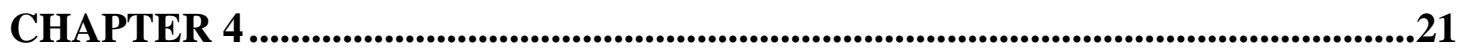

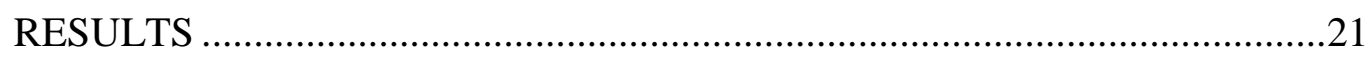

CHAPTER 5 ..........................................................................................................................32

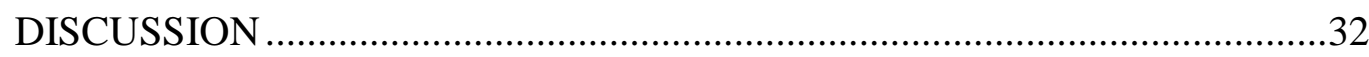

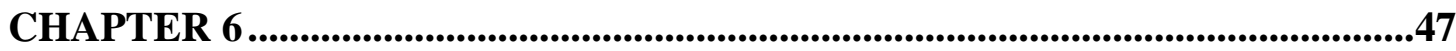

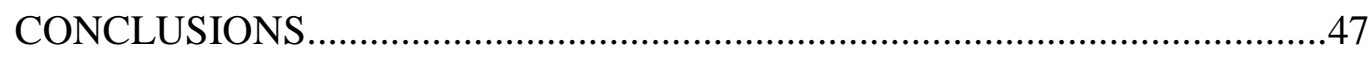

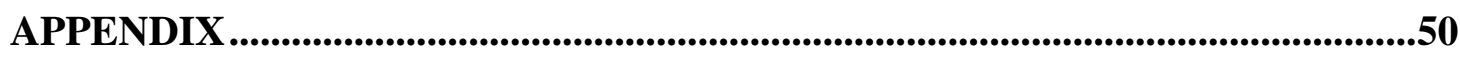

BIBLIOGRAPHY ....................................................................................................................66 


\section{LIST OF TABLES}

TABLE

PAGE

Table 1. Radiocarbon ages reported by the National Ocean Sciences Accelerator Mass Spectrometry facility from core $\mathrm{FHM}-112 . \delta^{13} \mathrm{C}$ values are from an aliquot of $\mathrm{CO}^{2}$

collected during sample combustion

Table 2. Downcore concentrations of ${ }^{137} \mathrm{Cs}$ activity and trace metal concentrations in core FHM-112 used to determine age markers during the last $\sim 200$ years. Values used to interpret pollution markers are highlighted for clarification..................................64

Table 3. Paleomarsh elevation (PME) estimates in standardized water level index (SWLI) and mean higher high water (MHHW) with a $2 \sigma$ uncertainty given by the Bayesian transfer function. Priors assigned to each sample are listed .65 


\section{LIST OF FIGURES}

\section{FIGURE}

Figure 1. (a) The study area includes our study site, Fox Hill Marsh, within Narragansett Bay (red box) and 16 study sites from previously published work within Long Island Sound (Edwards et al., 2004; Gehrels and van de Plassche, 1999; Kemp et al., 2015) which provide our reconstruction with a regional-scale modern foraminiferal training set. Locations of National Oceanic and Atmospheric Administration (NOAA) tide gauges used to interpret regional relative sea level (RSL) are shown (labeled blue circles; year CE of establishment is included). GPS site URIL provides a glacial isostatic adjustment rate for the region $(0.9 \mathrm{~mm} / \mathrm{yr}$; blue square; Karegar et al., 2016). The inset shows locations of previous RSL studies on the Atlantic coast. (b) Rhode Island's Narragansett Bay Estuary with the location of Fox Hill Marsh and Marsh Meadows shown on Conanicut Island in the lower bay. Sampled elevations were referenced to tidal datums at the Dutch Harbor NOAA benchmark in West Jamestown. Study sites from Donnelly and Bertness (2001) are located on Prudence Island and Rumstick Cove in upper Narragansett Bay. (c) Core and modern transect locations at Fox Hill Marsh. Solid red lines represent modern foraminifera transects (A-A' and B-B'). Dashed red lines correlate to the underlying stratigraphy shown in figure $2\left(\mathrm{X}-\mathrm{X}^{\prime}\right.$ and $\left.\mathrm{Y}-\mathrm{Y}^{\prime}\right)$. Blue lines represent modern bulk sediment transects used for $\delta^{13} \mathrm{C}$ analysis (A-E). 50

Figure 2. Annual RSL measurements recorded at tide-gauge stations in southern New England (geographic locations are shown in Figure 1a). All tide-gauge data was 
downloaded from the Permanent Service for Mean Sea Level (PSMSL). Average RSL from 1981-1990 CE is used as the reference period for each tide-gauge series

Figure 3. Modern assemblages of foraminifera from 18 samples at Fox Hill Marsh and their corresponding elevation (m mean higher high water). Some samples are slightly shifted by $0.002 \mathrm{~m}$ so that they can been seen. 7 of the 15 total taxa identified are presented. Jm: Jadammina macrescens; Tc: Tiphotrocha comprimata; TiSl: Trochammina inflata and Siphotrocha lobata; Mf: Milliammina fusca; H. spp.: Haplophragmoides spp.; A. spp.: Ammobaculites spp .53

Figure 4. Partitioning around medoids (PAM) cluster analysis recognized three assemblages of modern foraminifera at Fox Hill Marsh represented by colored boxes. (a) Elevational range of assemblages one (purple), two (green), and three (blue) defined by the highest and lowest elevation of samples assigned to each assemblage. Assemblage one ranges from -0.11 to $0.03 \mathrm{~m}$ mean higher high water (MHHW), assemblage two ranges from -0.14 to $0.11 \mathrm{~m}$ MHHW, and assemblage three ranges from -0.93 to -0.15 m MHHW. (b) The most abundant species ( $\geq 83 \%$ in any one sample; 7 of 15 taxa identified) of modern foraminifera at Fox Hill Marsh. Samples lacking an analog in the Kemp et al. (2015) training set are outlined in red

Figure 5. Measured $\delta^{13} \mathrm{C}$ values (relative to the Vienna Pee Dee Belemnite standard; VPDB) bulk sediment from Fox Hill Marsh modern transects (A-E) and the elevation associated with each sample. The right shaded area represents samples from a $\mathrm{C}_{4}$ 
environment with $\delta^{13} \mathrm{C}$ values less depleted than $-17 \%$. The left shaded area represents samples from a $\mathrm{C}_{3}$ environment with $\delta^{13} \mathrm{C}$ values more depleted than $-20 \%$. The dashed horizontal line represents the mean higher high water (MHHW) tidal datum.

Figure 6. Underlying stratigraphy at Fox Hill Marsh was determined by sampling and describing sediment cores (core number labelled at top). (a) Transect X-X' and (b) transect $\mathrm{Y}-\mathrm{Y}^{\prime}$ (also containing core FHM-112) follow the coring transects shown in

Figure 1c .56

Figure 7. Sea-level indicators and paleomarsh elevation (PME) estimates from core FHM-112. (a) Downcore organic content expressed as percent of loss on ignition (LOI). (b) Abundances of the four most common foraminifera species. The number of individuals counted from each sample are represented by colored bars. Samples that contained less than 40 individuals were excluded from the final reconstruction. (c) $\delta^{13} \mathrm{C}$ values of downcore bulk sediment relative to the Vienna Pee Dee Belemnite (VPDB) standard. Gray shaded regions represent values associated with environments dominated by $\mathrm{C}_{3}$ and $\mathrm{C}_{4}$ plant species. Symbol color represents the prior used to constrain PME estimated by the Bayesian transfer function (B-TF) based off modern $\delta^{13} \mathrm{C}$ values at Fox Hill Marsh. (d) PME (mean with 95\% credible interval) estimates from the B-TF that includes the prior given by bulk sediment $\delta^{13} \mathrm{C}$ measurements. Symbol color represents the prior assigned to each sample. (e) Measured dissimilarity between core samples and their closest modern analog. Dashed vertical lines represent percentiles of dissimilarity measured for all possible pairs of modern samples. Samples do not have a modern analog 
if they exceed the 20\% threshold (gray shaded region). Jm: Jadammina macrescens; TiSl: combined abundance of Trochammina inflata and Siphotrochammina lobata; Tc: Tiphotrocha comprimata; Mf: Milliammina fusca; MTL: mean tide level; MHHW: mean higher high water; HOF: highest occurrence of foraminifera; SWLI: standardized water level index 57

Figure 8. Downcore profiles of ${ }^{137} \mathrm{Cs}$ activity and trace metal and isotopic concentrations used to identify regional pollution markers used in the age-depth model. The lead isotope profile is shown twice with different scales for clarity. Gray shading represents the vertical uncertainty given to each chronohorizon with the associated age (year CE) and age uncertainty of each chronohorizon included next to the shaded area. Chronohorizons are distinguished from one another using horizontal dashed lines where necessary. Analytical uncertainties are smaller than the symbols used .58

Figure 9. Age-depth model developed for core FHM-112. The 95\% credible interval is represented by the blue envelope. Calibrated radiocarbon ages represent the $2 \sigma$ range between the youngest and oldest possible ages rather than the probability distribution of ages within the range. A detailed chronology for the last $\sim 150$ years is shown in the inset

Figure 10. (a) Relative sea level (RSL) reconstructed from Fox Hill Marsh and RSL measurements (annual mean) from the Newport tide gauge. Data points are represented by boxes of vertical and temporal uncertainty $(2 \sigma)$ from the Bayesian transfer function 
and age-depth model respectively. (b) The Errors-in-Variables Integrated Gaussian Process (EIV-IGP) model and change points (represented by light pink columns) superimposed on the proxy RSL reconstruction. Timings of estimated RSL change points for New York (dark pink; Kemp et al., 2017a), Roanoke, North Carolina (blue; Kemp et al., 2017b), and Florida (green; Gerlach et al., 2017) are also shown and overlap with our change point estimate of 1786-1907 CE. (c) Rate of relative sea-level change (including glacial isostatic adjustment (GIA) induced subsidence of $0.9 \mathrm{~mm} / \mathrm{yr}$ ) estimated by the EIV-IGP model .60

Figure 11. Detrended sea-level (left panels) and rates of detrended sea-level change $(\mathrm{mm} / \mathrm{yr}$; right panels) after removing estimates rates of glacial isostatic adjustment (listed in panel titles) in Rhode Island (a, d; this study), Connecticut (b, e; Kemp et al., 2015), and New York (c, f; Kemp et al., 2017a). Trends were estimated using the Errors-invariables Integrated Gaussian Process (EIV-IGP) model to ensure fair comparison between reconstructions and are presented here at identical scales for comparability...... 


\section{CHAPTER 1}

\section{Introduction}

The use of high-resolution proxy reconstructions of relative sea level (RSL) as late Holocene tide gauges (e.g. Barlow et al., 2013) was pioneered using salt-marsh sediments on the east coast of North America, resulting in abundant reconstructions (e.g. Gehrels, 1999; van de Plassche, 1991, 2000; van de Plassche et al., 1998; Varekamp and Thomas, 1998). Over the late Holocene (here defined as the past 4,000 years) the principal cause of RSL change along this coastline was glacial isostatic adjustment (GIA; e.g. Clark et al., 1978; Engelhart et al., 2009; Mitrovica and Peltier, 1991; Peltier, 1996) but it may also be influenced by dynamic oceanographic processes (e.g. Ezer et al., 2013; Yin \& Goddard, 2013) and fingerprints of ice melt (e.g. Kopp et al., 2010; Mitrovica et al., 2001). Existing high-resolution RSL reconstructions spanning a latitudinal gradient from northern Florida to Maine provide insight on the regional-scale physical processes that drive RSL changes in the North Atlantic Ocean on timescales longer than the limited duration of instrumental measurements (e.g. Gehrels et al., 2005; Kemp et al., 2011, 2014). However, there has been little investigation of how important local-scale processes are as drivers of late Holocene sea-level trends over spatial scales of 10s to 100s of km (e.g. Kemp et al., 2017b). Furthermore, few studies have sought to replicate RSL reconstructions within a region to explore the possibility that individual records may contain trends that are artifacts of the RSL reconstruction method including the quantitative method used to assign the relationship between sea-level indicators and a tidal level (e.g. Cahill et al., 2015; Kemp et al., 2017a) or related to chronological markers and age model choice (e.g. Wright et al., 2017). Therefore, producing more than 
one RSL reconstruction in a region is encouraged (Kemp et al., 2017b) to circumvent the issue of misinterpreting the spatial scale of RSL trends. Further, records from southern New England are limited in length to the past 2,200 years (e.g., Kemp et al., 2015, 2017a) and restrict our ability to evaluate earlier oscillations in RSL prior to the Medieval Climate Anomaly and Little Ice Age. Our goal is to address the current spatial and temporal patterns of RSL reconstructions in southern New England by producing a new record from salt-marsh sediment.

High salt-marsh environments accrete peat to keep pace with RSL rise and maintain their elevation in the tidal frame (e.g. Bricker-Urso et al., 1989; Redfield and Rubin, 1962). The resulting sequences of sediment are therefore archives of past RSL changes that can be reconstructed using sea-level indicators such as plants and foraminifera that are preserved in the peat (e.g. Redfield \& Rubin, 1962; Gehrels, 1994). High-resolution reconstructions of continuous RSL utilize continuous cores of salt-marsh peat and employ transfer functions on microfossils such as foraminifera to quantitatively estimate paleomarsh elevation (PME; i.e. marsh-surface elevation of a downcore sample at which it was originally deposited; e.g. Gehrels, 2000; Horton et al., 1999) with samplespecific age estimates provided by a chronology capable of decadal to centennial resolution. The precision of these methods is typically controlled by tidal range with errors ranging from $\pm 10-15 \%$ of greater diurnal tidal range (e.g. Barlow et al., 2013), allowing sites with small tidal ranges to identify smaller magnitude RSL changes. New methods that allow the use of a second proxy (e.g. $\delta^{13} \mathrm{C}$, diatoms) to constrain PME may allow further reduction in errors (e.g. Kemp et al., 2017a). The precision of RSL 
reconstructions can be improved by combining the proxy record with local tide-gauge measurements to produce a composite RSL history.

To investigate the possibility of small-scale spatial variations in RSL for southern New England, we ask three research questions: (1) are current reconstructions of Common Era RSL in Long Island Sound representative of RSL changes across southern New England? (2) did RSL deviate from a stable mean prior to the Common Era? and (3) have rates of RSL before the Common Era been greater than those during modern times ( 1800 CE to present)? We address these questions by producing a continuous, $\sim 3,300$ year high-resolution RSL record in Narragansett Bay, Rhode Island, using foraminifera and $\delta^{13} \mathrm{C}$ values of bulk sediment from a dated core of salt-marsh peat from Fox Hill Marsh (lower Narragansett Bay; Figure 1). RSL was reconstructed using a composite chronology and a multi-proxy approach to reduce vertical uncertainty. We combined the proxy-based reconstruction with instrumental RSL measurements to create a merged RSL record that allowed us to estimate trends and rates of change with full consideration for sources of uncertainty. The new RSL record was corrected for GIA $(0.9 \mathrm{~mm} / \mathrm{yr})$ to compare sea-level trends from sites within Long Island Sound (Kemp et al., 2015; Kemp et al., 2017a). The reconstructions agree that rates of sea-level rise are faster now than at any time over the Common Era. However, there is a disagreement between each record on the magnitude, timing, and number of oscillations of regional sea level. Our new Rhode Island RSL record shows evidence of multiple sea-level oscillations that are not seen in the Connecticut record, indicating that rates of rise and fall are not consistent across southern New England. We explore the possible contributions to these differences from physical processes and artifacts due to the method of reconstructing RSL. We 
conclude that the high density of radiocarbon dates used to develop our chronology and/or the vertical resolution of our reconstruction is the primary reason the reconstructions disagree. Until a record that is comparable in length and resolution offers further evidence, we cannot definitively conclude that southern New England RSL is affected by regional or local processes that drive the differences between the reconstructions. 


\section{CHAPTER 2}

\section{Study Area}

We selected lower Narragansett Bay as our study site for three reasons. Firstly, this area lies outside of Long Island Sound (Figure 1a) where previous work shows that RSL reconstructions (e.g., Kemp et al., 2015) may be contaminated by paleo tidal range changes (Kemp et al., 2017a). Secondly, vertical uncertainties in RSL reconstructions are primarily a function of tidal range, offering low errors in reconstructions produced from sites with small tidal ranges (Barlow et al., 2013). Therefore, great diurnal tidal ranges (mean lower low water to mean higher high water; MLLW; MHHW) of 0.9-1.2 $\mathrm{m}$ in lower Narragansett Bay offer an opportunity to improve the precision of RSL reconstructions in southern New England compared to the existing Kemp et al. (2015) reconstruction that was produced at a site with a tidal range of $1.75 \mathrm{~m}$. Thirdly, sites within the bay contain thick accumulations of salt-marsh peat that span beyond the Common Era (Donnelly \& Bertness, 2001), ideal for providing high-resolution records of continuous RSL change that extend beyond the current $\sim 2,200$-year record in Connecticut.

The modern-day Narragansett Bay Estuary (Figure 1b) comprises $412 \mathrm{~km}$ of Rhode Island's total coastline, characterized by a series of islands and coves in which salt marshes typically form. Tidal influence extends $\sim 45 \mathrm{~km}$ up the bay to the Seekonk River,

just north of Providence, RI. The bay has a mean depth of $\sim 8 \mathrm{~m}$ with a maximum of $56 \mathrm{~m}$ (URIOMP). It experiences a temperate climate with a mean annual air temperature of $\sim 9-$ $11^{\circ} \mathrm{C}$ and mean annual precipitation of $\sim 1,000-1,200 \mathrm{~mm}$ (RIDEM, 2017). The bay, while receiving freshwater input from four rivers, is open at the southern end to the 
Atlantic Ocean, resulting in an average salinity of 29-31 (URIOMP, 2017). Narragansett Bay was sculpted during the last glaciation as the Laurentide Ice Sheet moved southward into the Atlantic Ocean, creating the east and west passages of the bay. The Laurentide Ice Sheet had retreated from the southern Rhode Island coast by 20,000 years BP (Ridge, 2003) and marine water advanced into Narragansett Bay by $~ 7,100$ years BP (Peck \& McMaster, 1991).

We selected Fox Hill Marsh as our study site, because of the sites investigated, it yielded the thickest sequences of high salt-marsh peat that included well-preserved plant macrofossils for radiocarbon dating. Fox Hill Marsh, sheltered in a small cove on the southwest of Conanicut Island within Narragansett Bay, surrounds a tidal pond that is connected to the bay by a small northern inlet ( $<20 \mathrm{~m}$ wide; Figure $1 \mathrm{c})$. A north-facing beach and elevated uplands used as a campsite and farmland surround the marsh. The unvegetated tidal flats within the pond transition directly to middle to high salt-marsh sediment at Fox Hill Marsh, most likely due to erosion with sediment slumping that results in an eroding cliff face of the extensive high-marsh platform. The distribution of $\mathrm{C}_{4}$ and $\mathrm{C}_{3}$ species displayed at Fox Hill Marsh is similar to vegetation communities documented at brackish and oligohaline marshes within Narragansett Bay (e.g. Crain et al., 2008; Wigand et al., 2003; Wozniak et al., 2006) and elsewhere in southern New England (e.g. Niering and Warren, 1980; Nixon, 1982). C $_{4}$ plant species Spartina alterniflora (short form; abundant near the lower portion of the platform), Spartina patens, Distichlis spicata, and the $\mathrm{C}_{3}$ species Salicornia virginica characterize the highmarsh platform from approximately $0.10 \mathrm{~m}$ below mean high water (MHW) to MHHW. The highest marsh above MHHW to the highest occurrence of foraminifera (HOF) is 
vegetated by $\mathrm{C}_{3}$ species (Juncus gerardii, Schoenoplectus spp., Aster tenuifolius, Iva fructescens, Phragmites australis, and Typha spp.).

Fox Hill Marsh experiences semidiurnal tides with a great diurnal tidal range of 1.17 m (NOAA station datum 8453742, West Jamestown, RI; CO-OPS, 2013a). The Newport tide gauge (NOAA station 8452660; 6 km east of Fox Hill Marsh; see Figure 1b) offers an instrumental record of annual average RSL change from $1931 \mathrm{CE}$ to present. The great diurnal tidal range at Newport is also $1.17 \mathrm{~m}$ (CO-OPS, 2013b). Two approaches are available to combine tide-gauge measurements with proxy RSL data: 1) obtain a regional RSL average using multiple tide gauges or; 2) use RSL measurements from a single, local tide gauge. To determine whether to use regional or local tide-gauge data, RSL measurements from the Newport, Providence, Woods Hole, New London, Bridgeport, and Montauk tide gauges were downloaded from the Permanent Service for Mean Sea Level (PSMSL) to compare annual RSL trends during the past $\sim 85$ years (Figure 3; PSMSL, 2017). We used average RSL from 1981-1990 CE as the reference period for each tide-gauge series because it was the most recent decade of data shared by all the tide gauges. 


\section{CHAPTER 3}

\section{Methods}

\subsection{Modern Sea-level Indicators}

\subsubsection{Foraminifera}

The vertical zonation of salt-marsh foraminifera within the tidal frame is the result of species' tolerance to tidal inundation and frequency, and thus elevation (Scott \& Medioli, 1978; Gehrels, 1994; Edwards et al., 2004; Wright et al., 2011). Therefore foraminifera preserved in sequences of salt-marsh sediment are a proxy for the elevation in the tidal frame at which a sample was originally deposited (termed PME) and can therefore be employed to reconstruct RSL (Gehrels, 1994, 1999; de Rijk \& Troelstra, 1997; Kemp et al., 2009, 2011, 2013a, 2015, 2017a). Reconstructing PME is reliant upon the availability, accuracy, and appropriateness of a modern training set composed of paired observations of contemporary foraminifera and tidal elevation.

We used a regional-scale training set based on a compilation of 254 surface samples of dead foraminiferal assemblages from 16 sites in Connecticut and New York (Kemp et al., 2015; Figure 1a) in this study because it provided the necessary modern dataset to estimate PME for our reconstruction. Kemp et al. (2015) combined 162 original samples with published data (Edwards et al., 2004; Gehrels and van de Plassche, 1999) summarized by Wright et al. (2011), consisting of 92 samples from four sites in Connecticut. In this modern training set, elevation is expressed as a standardized water level index (SWLI), which allows samples collected at sites with different tidal ranges to be combined into a regional-scale dataset (e.g. Horton, 1999). Here, mean tide level $(\mathrm{MTL})=0 \mathrm{SWLI}, \mathrm{MHHW}=100 \mathrm{SWLI}$, and the HOF (in any of the 254 samples $)=155$ 
SWLI.

We collected sediment samples along two transects at Fox Hill Marsh to compare local assemblages of modern salt-marsh foraminifera to those within the regional training set. The purpose of this comparison is to judge if the existing regional-scale dataset of Kemp et al. (2015) could reasonably be applied to interpret assemblages of foraminifera preserved in cores of salt-marsh sediment from Rhode Island. The availability of an independent modern dataset from Fox Hill Marsh provides a dataset with which to test the accuracy of PME reconstructions developed using the existing modern training set.

Each transect spanned the unvegetated tidal flat, onto the middle to high-marsh platform vegetated by stunted S. alterniflora at lower elevations and S. patens and $D$. spicata at higher elevations, and into dense $P$. australis patches located in the upland (Figure 1c). Sediment was sampled at regular changes in elevation $(\sim 10 \mathrm{~cm})$ to capture variations in foraminiferal assemblages (e.g. Scott and Medioli, 1978). The surface elevation of each modern sample was measured relative to North American Vertical Datum of 1988 (NAVD88) by leveling to a permanent benchmark (West Jamestown, RI 3742 A 1977) less than $1 \mathrm{~km}$ away at Dutch Harbor on Jamestown, RI (Figure 1b) using a Leica GS15 real-time kinematic (RTK) GPS (error $\pm 0.02 \mathrm{~m}$ ). Tidal datums at Fox Hill Marsh were determined to be comparable to NOAA station datum 8453742 West Jamestown, RI (CO-OPS, 2013a) after measuring 6-minute water levels at Fox Hill Marsh using an automatic water logger, deployed between June 22, 2016 and September 2, 2016 (corrected for variations in atmospheric pressure measured using a barometric pressure monitor). 
Surface samples $\left(\sim 5 \mathrm{~cm}^{2}\right.$ by $\sim 1-\mathrm{cm}$ thick) were treated with rose Bengal (for staining live foraminifera), preserved in buffered ethanol (e.g. Walton, 1952; Horton \& Edwards, 2006) and stored at $4^{\circ} \mathrm{C}$ prior to analysis. During foraminiferal analysis, modern samples are sieved to isolate sediment between $63 \mu \mathrm{m}$ and $500 \mu \mathrm{m}$ and divided into eight equally representative sub-samples using a wet splitter (Scott \& Hermelin, 1993). Live (i.e. stained) and dead foraminifera were identified and counted ( $\geq 100$ dead individuals/sample, or until the sample is depleted) wet under a microscope. Species identification followed the taxonomy employed by Edwards and Wright (2015), Edwards et al. (2004b), Gehrels and van de Plassche (1999), and Wright et al. (2011). Consistent with the training set of Wright et al. (2011), Trochammina inflata and Siphotrocha lobata species were merged into a single group after counting, as were all species of the genus Haplophragmoides. Individuals of the genus Ammobaculites were placed into a single group as tests are often broken in fossilized sediments and difficult to identify to the species level (Kemp et al., 2009; Wright et al., 2011).

To compare the vertically-zoned assemblages of modern foraminifera at Fox Hill Marsh to other datasets in New England (Edwards et al., 2004; Gehrels, 1994; Wright et al., 2011), we determined the number and composition of modern foraminiferal assemblages by partitioning around medoids (PAM) analysis using the 'cluster package' (Maechler et al., 2016) in R. This technique quantitatively and objectively assigns individual samples to clusters (i.e. ecological zones) and calculates a value (known as a silhouette width) between -1 (incorrectly grouped) and 1 (appropriately grouped) of a sample's classification within the overall cluster (Kaufman \& Rousseeuw, 1990). 
The percent abundance of dead species is used as the input for PAM. PAM generates groups by assigning individual samples to clusters that each has a corresponding silhouette plot and value. The highest average silhouette width assigned to the clusters objectively defined the number of assemblages within the modern dataset. The elevation data taken at each sample location defines the vertical zonation of each objectively-determined assemblage.

We used the modern analogue technique (MAT) and bootstrapping cross validation $(n=10,000)$ on the regional training set to check for modern analogues using the local modern dataset from Fox Hill Marsh. Samples are determined to be reliable if the sample's modern analog falls within the $20^{\text {th }}$ percentile of dissimilarity (squared chisquare metric) while samples that have a minimum dissimilarity greater than the $20^{\text {th }}$ percentile are considered to lack a modern analog, in which case they are removed from

the reconstruction (e.g. Kemp et al., 2013a, 2015; 2017a; Overpeck et al., 1985; Watcham et al.,2013).

\subsubsection{Stable Carbon Isotopes in Bulk Sediment}

Species of salt-marsh vegetation, like foraminifera, have different tolerances to the duration and frequency of tidal inundation, forming conspicuous vegetation zones (e.g. Bertness, 1992). In Mid-Atlantic and New England salt marshes (including Fox Hill Marsh) the MHHW tidal boundary marks the separation of ecological zones characterized by $\mathrm{C}_{4}$ species (e.g. S. patens and D. spicata; below $\mathrm{MHHW}$ ) and $\mathrm{C}_{3}$ species (e.g. J. gerardii and P. australis; above MHHW; Kemp et al., 2012c). Along with the different photosynthetic pathways of $\mathrm{C}_{4}$ and $\mathrm{C}_{3}$ plants (Smith and Epstein, 1971), salt- 
marsh sediment retains the carbon signature of the above and below ground plant biomass that formed it (Chmura \& Aharon, 1995) and is useful in constraining PME estimates for RSL reconstructions (Kemp et al., 2013a, 2017a).

To determine the local threshold $\delta^{13} \mathrm{C}$ values across the MHHW tidal datum we collected bulk surface-sediment samples along five transects (A-E) at Fox Hill Marsh (Figure 1c). Transects began in high-marsh vegetation communities (composed of $S$. patens and $D$. spicata) to capture bulk sediment $\delta^{13} \mathrm{C}$ values that are dominantly $\mathrm{C}_{4}$ below MHHW, and end in the transitional upland plant communities (composed of $I$. fructescens, P. australis, Typha spp., Schoenoplectus spp., and terrestrial plants) to capture bulk sediment $\delta^{13} \mathrm{C}$ values that are dominantly $\mathrm{C}_{3}$ above $\mathrm{MHHW}$. Each transect consists of six randomly-spaced samples taken where there were noticeable changes in plant assemblage (e.g. $100 \%$ S. patens to $70 \%$ S. patens $/ 30 \%$ D. spicata) and end where $\mathrm{C}_{3}$ vegetation dominated (e.g. $100 \%$ P. australis; $50 \%$ I. fructescens $/ 50 \%$ J. gerardii). Sample elevations were measured using the same method and instruments discussed in section 3.1.1. Samples were stored at $4{ }^{\circ} \mathrm{C}$ to prevent degradation prior to analysis. Bulk sediment samples were dried at $\sim 40^{\circ} \mathrm{C}$ for 48 hours and ground to a fine, homogenized powder with a mortar and pestle. $\sim 2 \mathrm{~mL}$ subsamples of dried sediment were treated with $5 \mathrm{ml}$ of $6 \mathrm{~N}(20 \% \mathrm{w} / \mathrm{w}) \mathrm{HCl}$ for 12 hours at room temperature. Samples were then repeatedly centrifuged, decanted, and rinsed with de-ionized water to remove $\mathrm{HCl}$ while retaining fine particles (modification of the rinse method in Brodie et al., 2011). Following removal of inorganic carbon, $\delta^{13} \mathrm{C}$ and organic carbon content were measured on dried samples using an Isoprime 100 Isotope Ratio Mass Spectrometer interfaced with a Micro Vario Elemental Analyzer. The carbon isotope composition was 
expressed as a part per thousand (per mil) deviation $\left(\delta^{13} \mathrm{C} \%\right.$ ) from Vienna Pee Dee Belemnite (VPDB) standard, where

$$
\delta^{13} C=\left[\frac{R_{\text {sample }}-R_{\text {standard }}}{R_{\text {standard }}}\right] * 1000
$$

and $\mathrm{R}$ is the ratio ${ }^{13} \mathrm{C} /{ }^{12} \mathrm{C}$ in either the sample or a reference standard (VPDB). Standard reference materials were used to check for instrument drift in each run and to correct for instrument offset. Check standards were included after every ten samples during instrument runs. Average recoveries were $99 \pm 2.7 \%$ for percent carbon and $100 \pm 0.1 \%$ for $\delta^{13} \mathrm{C} \%$.

\subsection{Sediment Coring}

The sub-surface stratigraphy at Fox Hill Marsh was mapped extensively by describing sediment recovered in gouge cores or Russian cores where sediment was difficult to recover (Figure 1c) using the Tröels-Smith (1955) system of classification. A well-developed and uniform salt-marsh peat was revealed for the entirety of the study site (Figure 2). We selected core FHM-112 for further analysis as it contains the deepest sequence of continuous salt-marsh peat within our study site, providing us with the longest RSL record. We collected the core in overlapping $50 \mathrm{~cm}$ increments with a Russian corer to reduce contamination and sediment compaction during core recovery. All core samples were transferred to cut PVC tubes, wrapped in plastic, labeled, and stored at $4{ }^{\circ} \mathrm{C}$ for preservation. Core-top elevations were measured using the same method and instruments discussed in section 3.1.1. Downcore organic content was measured by loss on ignition (LOI) using standard procedures (Head, 1980). 


\subsection{Core Chronology}

We radiocarbon-dated in-situ rhizomes and stems of salt-marsh plants (primarily D. spicata) from discrete depths of FHM-112 using radiocarbon (e.g. Redfield \& Rubin, 1962; Redfield, 1965; Donnelly \& Bertness, 2001). These macrofossils grew close to the salt-marsh surface (within 4 cm; e.g. Kemp et al., 2013b; van de Plassche et al., 1998) and are therefore appropriate material for radiocarbon dating paleomarsh surfaces that were inhabited by the salt-marsh foraminifera that we used to reconstruct PME. 10-cm core sections were dissected in 1-cm increments and sorted through for the most suitable dating material (i.e. large rhizomes, multiple rhizomes in a $1 \mathrm{~cm}$ thick slice, and woody stem chunks). We selected samples for radiocarbon dating to give an approximately even spacing of samples throughout the core. These selected samples were further processed by cleaning them under a microscope to remove younger root material and adhered sediment, after which the sample was dried at $\sim 40^{\circ} \mathrm{C}$, weighed, and sent to the National Ocean Sciences Accelerator Mass Spectrometry (NOSAMS) facility for standard acidbase-acid pretreatment and accelerator mass spectrometry (AMS) radiocarbon dating.

Due to a plateau in the radiocarbon calibration curve, material younger than $\sim 1600 \mathrm{CE}$ returns multiple calibrated ages with large uncertainty (Stuiver \& Pearson, 1993). To overcome this impediment to developing a precise chronology of sediment accumulation in FHM-112, we identified chronohorizons of known age using downcore concentrations of lead isotopes, heavy metals such as lead, mercury, copper, and vanadium (e.g. Kemp et al., 2013a, 2015, 2017a), and downcore activity of ${ }^{137}$ Cs. Sediment samples (1-cm thickness) at 2-3 cm intervals from the upper $70 \mathrm{~cm}$ of FHM112 were used to identify chronohorizons. After removing visible plant material, each 
sediment sample was dried at $\sim 40^{\circ} \mathrm{C}$, ground to a fine, homogenized powder with a mortar and pestle, weighed, and sent to SGS Minerals Services Geochemical Laboratory. At the laboratory, the samples underwent acid digestion and elemental and isotopic abundances were measured using inductively coupled plasma emission spectrometry (ICP-OES) and inductively coupled plasma mass spectrometry (ICP-MS). Additionally, sediment from the top $20 \mathrm{~cm}$ of the core was sampled at $1 \mathrm{~cm}$ intervals, dried at $\sim 40^{\circ} \mathrm{C}$, ground to a fine, homogenized powder with a mortar and pestle, and sent to UNC Coastal Studies Institute to measure ${ }^{137} \mathrm{Cs}$ activity by direct gamma counting using the methods and instruments described in Corbett et al. (2009).

Downcore trends of lead isotope ratios, heavy metal concentrations, and ${ }^{137} \mathrm{Cs}$ activity were identified and assigned to known historical pollution events. The principal source of metal input in high-marsh sediments is from the atmosphere (via prevailing westerlies; assumed constant) as these sediments spend less time inundated by the tides than the low marsh (e.g. Bricker-Urso \& Nixon, 1984) and we assume that no further isotopic fractionation took place during transport (e.g. Kemp et al., 2012b; Lima et al., 2005b). We interpreted regional pollution markers (e.g. onset of industrialization) where similar downcore trends could be seen among several heavy metal profiles (e.g. increase in concentrations above background values; e.g. Kemp et al., 2017a). Trends and/or features, rather than absolute values, are used because pollution per unit of production does not remain constant through time. Age uncertainties assigned to each age marker account for the time between pollution emission and successive deposition. Depth uncertainties are assigned to age markers to account for the range of possible sample depths that an individual pollution trend represents in the core. 
Stable lead isotopes $\left({ }^{206} \mathrm{~Pb}:{ }^{207} \mathrm{~Pb}\right)$ demonstrate a wide-spread regional signal in northeast U.S. (Lima et al., 2005b; Kemp et al., 2012a) and Canadian sediments (Gobeil, Tessier, \& Couture, 2013), providing reliable age markers to establish recent chronologies in RSL reconstructions from the northeastern United States (Kemp et al., $2013,2015,2017)$. We assign the age of $1858 \pm 5 \mathrm{CE}$ to the initial peak in ${ }^{206} \mathrm{~Pb} /{ }^{207} \mathrm{~Pb}$, which reflects the maximum relative contribution of mining and smelting activities of the Upper Mississippi Valley to national U.S. production during the late 1850s (Kemp et al., 2012b). A minimum and recent maximum in ${ }^{206} \mathrm{~Pb} /{ }^{207} \mathrm{~Pb}$ is attributed to changing isotopic signatures of leaded gasoline and are assigned ages of $1965 \pm 5$ and $1980 \pm 5 \mathrm{CE}$, respectively. Changes reflect the introduction of leaded gasoline with a relatively constant isotopic ratio from 1923 to 1965 and a ratio increase up to 1980 (Lima et al., 2005b). The initial occurrence and recent peak of ${ }^{137} \mathrm{Cs}$ activity are assigned $1954 \pm 2 \mathrm{CE}$ and $1963 \pm 1 \mathrm{CE}$, respectively, which reflect the initial occurrence of nuclear weapons testing and the maximum fallout after the 1963 Limited Test Ban Treaty, respectively (Corbett and Walsh, 2015; Lima et al., 2005a). The initial rise in lead, mercury, copper, and vanadium concentrations from low background values was interpreted as the onset of industrial activity in the mid- to late-1800s and assigned an age of $1875 \pm 25 \mathrm{CE}$. The most recent peak seen in lead, mercury, copper, and vanadium concentrations is interpreted as the implementation of the 1974 Clean Air Act and is assigned an age of 1974 \pm 5 CE. We use the initial peak in mercury to assign an age $1900 \pm 10 \mathrm{CE}$ based on the ${ }^{210} \mathrm{~Pb}$ chronology developed by Varekamp et al. (2003) that showed the onset of mercury pollution in eastern Connecticut ranged from 1890-1910 CE.

We produced an age-depth model using 'Bchron' (Haslett \& Parnell, 2008), 
which interpolates age uncertainties between dated samples and summarizes a resulting suite of equi-probable chronologies to estimate sample ages with a $95 \%$ credible interval. We calibrated the radiocarbon dates using the IntCal13 dataset (Reimer et al., 2013) to obtain probability distributions. We assigned a normal probability distribution to pollution markers with no weighting applied to any of the age estimates. A depth correction of $2 \mathrm{~cm}$ was applied to all radiocarbon samples to compensate for the depth at which rhizomes (of a living plant at the surface) sit below the surface. A sample thickness of $4 \mathrm{~cm}$ was used to account for the depth range over which a rhizome may occur.

\subsection{Reconstructing Relative Sea Level}

Core FHM-112 was subsampled in $3 \mathrm{~cm}$ increments for fossilized foraminifera and stored at $4^{\circ} \mathrm{C}$ until analysis. Sample preparation and counting followed the approach used for surface samples apart from staining with rose Bengal. Samples with fewer than 40 individuals were excluded from further analysis because they may not represent a reliable and in situ assemblage (e.g. Kemp \& Telford, 2015). Downcore bulk sediment sampled at $5 \mathrm{~cm}$ intervals determined $\delta^{13} \mathrm{C}$ trends throughout the core. Sample preparation and analysis followed the procedure used for surface bulk-sediment samples described in section 3.1.2.

We follow the model implemented by Kemp et al. (2017a) to reconstruct RSL using the existing Bayesian transfer function (B-TF) of Cahill et al. (2016). The B-TF was applied to downcore samples consisting of foraminifera (expressed in raw counts) to generate PME estimates in core FHM-112 using the previously established regional training set. The reliability of the PME estimates were determined using the MAT 
method described in section 3.1.1. A prior specification for PME is needed to apply the B-TF to downcore samples, which can be informed by the modern training data. Here, we utilize the organic nature of the core sediment and presence of salt marsh foraminifera that indicated all samples accumulated above MTL (SWLI=0) but below the HOF (SWLI=155). Priors are further constrained by downcore $\delta^{13} \mathrm{C}$ values of bulk sediment and are assigned based on persistent downcore $\delta^{13} \mathrm{C}$ values, rather than treated in isolation. $\delta^{13} \mathrm{C}$ values determined if a sample originally formed below or above MHHW and provide the B-TF with a further prior constraint for estimating PME in three possible ways: 1) Samples with a $\mathrm{C}_{3}$ signature containing foraminifera are assigned an informative prior of MHHW to the HOF (100-155 SWLI). 2) Samples with a $\mathrm{C}_{4}$ signature are assigned an informative prior of MTL to MHHW (0-100 SWLI). 3) Samples with a mixed $\delta^{13} \mathrm{C}$ signature are assigned an uninformative prior of MTL to the HOF $(0-155$ SWLI).

The B-TF returns a reconstruction of sample elevations with a sample-specific uncertainty (95\% credible interval) which must be converted into PME (m MHHW) from SWLI, where

$$
\mathrm{PME}=\left(\frac{\mathrm{SWLI}}{100} *\left(M H H W_{b}-M T L_{b}\right)\right)-\left(M H H W_{b}-M T L_{b}\right)
$$

and $\mathrm{MHHW}_{\mathrm{b}}$ and $\mathrm{MTL}_{\mathrm{b}}$ are tidal datums at site $\mathrm{b}$. PME estimates provided by the B-TF are used to calculate RSL using the equation:

$$
R S L_{i}=A l t_{i}-P M E_{i}
$$

where $\mathrm{Alt}_{i}$ is the measured altitude of sample $i$ and $\mathrm{PME}_{i}$ is the calculated PME for sample $i$, both expressed relative to MHHW. Sample altitudes are determined by subtracting sample depth (down core) from measured elevation of the core top, relative to 
MHHW. Each 1-cm thick sample in FHM-112 was assigned an age estimate from the age-depth model with an associated uncertainty (95\% credible interval).

\subsection{Quantifying Relative Sea-Level Trends}

\subsubsection{Tide Gauge Data}

We computed decadal averages of RSL (2007-2016 CE as the reference period as it represents the most recent changes in RSL) using annual measurements from the Newport tide gauge to combine with our proxy RSL dataset. Decadal averages have estimated vertical uncertainties (standard deviation of RSL for each decade; $2 \sigma$ ) and age uncertainties that we conservatively treat as a $2 \sigma$ range. Instrumental measurements of averaged decadal RSL are combined with the proxy dataset to determine consistency and provide confidence in the reconstruction.

\subsubsection{EIV-IGP and Change Point Analysis}

We use an Errors-in-Variables Integrated Gaussian Process (EIV-IGP) model to appropriately estimate quantitative RSL trends, with uncertainties, through time (Cahill et al., 2015). EIV-IGP generates a near-continuous time series of RSL and rates of RSL change for the combined (proxy plus tide gauge) dataset with full consideration of all sources of uncertainty. The EIV-IGP approach accounts for the uneven spacing of data points through time and their associated age range, vertical uncertainty, and probability distribution. This model allows us to remove linear trends, such as from GIA, by accounting for the co-variance in uncertainties that is introduced by removing GIA trends. Additionally, we applied errors-in-variables change-point analysis following the 
approach described in Kemp et al. (2013) to our data to objectively distinguish time periods of distinct rates in RSL change. This approach treats RSL trends as linear sequences joined together at change points, estimated quantitatively from the RSL data with uncertainties. 


\section{CHAPTER 4}

\section{Results}

\subsection{Modern Foraminifera}

We identified 15 taxa of agglutinated foraminifera in the dead assemblage of 18 surface sediment samples collected at Fox Hill Marsh (Figure 3) across an elevational range of $-0.39-0.11 \mathrm{~m}$ MHHW. PAM determined that the modern assemblages at Fox Hill Marsh are best grouped into three distinct assemblages of foraminifera (Figure 4a) based on the highest average silhouette width (0.42) calculated for 2-8 groups. Percent values presented here represent average species abundance for samples within their assigned assemblage. The first assemblage recognized by PAM contains five samples (4b) and has an average silhouette width of 0.50 . It is defined by the presence of $T$. comprimata (47.9\%) and Haplophragmoides spp. (21.2\%), which account for a minimum of $57.6 \%$ in each sample. Assemblage one also contains low abundances of J. macrescens (7.2\%), T. inflata and S. lobata (10.7\%), and M. fusca (7.1\%). The elevational range of assemblage one is $-0.11-0.03 \mathrm{~m}$ MHHW (Figure 4a) and occurs in a high salt-marsh environment. The second assemblage recognized by PAM contains eight samples (Figure 4b) and has an average silhouette width of 0.21 . It is defined by the presence of $J$. macrescens (38.6\%) with T. comprimata (23.1\%). Assemblage two also contains low abundances of T. inflata and S. lobata (9.9\%), Haplophragmoides spp. (9.5\%), Ammobaculites spp. (9.9\%), and M. fusca (4.4\%). The elevational range of assemblage two spans from -0.14 to $0.11 \mathrm{~m} \mathrm{MHHW} \mathrm{(Figure} \mathrm{4a)} \mathrm{and} \mathrm{occurs} \mathrm{in} \mathrm{a} \mathrm{high} \mathrm{salt-marsh}$ environment. The third assemblage recognized by PAM contains five samples (Figure 4b), has an average silhouette width of 0.67 , and is defined by the presence of $M$. fusca 
(38.3\%) and J. macrescens (29.4\%). Assemblage three also contains low abundances of T. inflata and S. lobata (15.5\%) and T. comprimata (9.0\%). The elevational range of assemblage three spans from -0.39 to $-0.15 \mathrm{~m}$ MHHW (Figure 4a) and represents a low salt-marsh environment.

To check the Fox Hill Marsh modern dataset for analogs, we applied the MAT to the regional-scale training set. Application of the MAT demonstrates that the regionalscale modern training set provides a modern analog for 16 of the 18 surface samples at Fox Hill Marsh. Samples two (assemblage one) and five (assemblage two) from transect A-A' (Figure 1c) do not fall below the $20^{\text {th }}$ percentile threshold and lack an analog in the 254-sample modern training set. Sample two has a high abundance of $T$. comprimata (55\%) and completely lacks $T$. inflata and S. lobata. This sample likely lacks an analog because samples in the Kemp et al. (2015) training set with a high abundance of $T$. comprimata ( $\geq 40 \%$ ) also contain a high abundance of $T$. inflata and S. lobata, which consists of a minimum of $15 \%$ of the assemblage for a sample. Sample five likely lacks an analog because a high abundance of the low-marsh and tidal-flat foraminifer Ammobaculites spp. (24.5\%) is found in a sample that is dominated by the high-marsh species J. macrescens (48.1\%). While large abundances of Ammobaculites spp. ( $\geq 20 \%)$ occur in the Kemp et al. (2015) modern training set, these samples are associated with absent or a low abundance of J. macrescens (maximum of 35\%).

\subsection{Stable Carbon Isotopes in Modern Bulk Sediment}

To determine the $\delta^{13} \mathrm{C}$ threshold values used to assign priors to downcore samples, we measured surface bulk-sediment $\delta^{13} \mathrm{C}$ values in a total of 30 samples from 
five transects (A-E). These transects were positioned to span from the high salt-marsh into the surrounding freshwater upland because the MHHW tidal datum marks the boundary between plant communities dominated by $\mathrm{C}_{3}$ and $\mathrm{C}_{4}$ species. Measured $\delta^{13} \mathrm{C}$ values ranged from $-16.3 \%$ to $-28.1 \%$ (Figure 5). Bulk sediment with $\delta^{13} \mathrm{C}$ values less depleted than $-17.0 \%$ occurs exclusively below MHHW and bulk sediment with $\delta^{13} \mathrm{C}$ values more depleted than $-20.0 \%$ predominantly ( 14 of 15 samples) occurs above MHHW. Bulk sediment with a $\delta^{13} \mathrm{C}$ value between $-17.0 \%$ and $-20.0 \%$ cannot reliably distinguish between deposition above or below MHHW. These results determine the threshold $\delta^{13} \mathrm{C}$ values used to assign priors to downcore samples in one of three ways: 1) Bulk-sediment samples with $\delta^{13} \mathrm{C}$ values less depleted than $-17.0 \%$ are interpreted to have formed below MHHW because $\mathrm{C}_{4}$ plants were the dominant type of vegetation and were assigned a prior of MTL to MHHW (0-100 SWLI). 2) Bulk-sediment samples with a $\delta^{13} \mathrm{C}$ value more depleted than $-20.0 \%$ and that contained foraminifera are interpreted to have formed above MHHW because $\mathrm{C}_{3}$ plants were the dominant type of vegetation and were assigned a prior of MHHW to HOF (100-155 SWLI). 3) Samples with $\delta^{13} \mathrm{C}$ values between $-17.0 \%$ and $-20.0 \%$ and contained foraminifera were assigned an uninformative prior of MTL to HOF (0-155 SWLI).

\subsection{Stratigraphy at Fox Hill Marsh}

We described the stratigraphy underlying Fox Hill Marsh using 60 cores $(0.34-$ $3.70 \mathrm{~m}$ long). The stratigraphy is consistent among cores and is characterized by thick sequences of brown to black high salt-marsh peat overlying glacial till, composed of silty sand and gravel that we interpret to be an incompressible substrate (Figure 6). Basal peat 
is typically $\sim 10-20 \mathrm{~cm}$ of dark brown to black amorphous peat that varies between lacking in visible and identifiable plant macrofossils or containing identifiable plant material (X-X' transect; Figure 6a). Basal peat described at core locations close to Fox Hill Pond (Y-Y' transect; Figure 6b) is less decomposed and comprised of slightly more sand or silt. Cores near the barrier beach in the southwestern portion of Fox Hill Marsh contain sand layers that we interpret as likely deposited by storm-surge overwash. No evidence of such layers is observed in visual descriptions or x-ray imaging of cores outside of this small area of the marsh. We interpret salt-marsh development occurred following the marine transgression of a former surface that resulted in the formation of high salt-marsh peats directly above glacial sediments.

\subsection{Foraminifera and Bulk Sediment $\delta^{13} \mathrm{C}$ in FHM-112}

The measured core-top elevation of collected core FHM-112 (Figure 7) was -0.18 $\mathrm{m}$ MHHW and is comprised of $3.23 \mathrm{~m}$ of brown high-marsh peat containing wellpreserved plant stems (unidentified) and rhizomes (primarily identified as D. spicata), below which was $0.13 \mathrm{~m}$ of dark brown to black, highly decomposed and saturated peat with large rhizomes. At the base of recovery was a gray, silty sand with small root material in the top $\sim 4 \mathrm{~cm}$ that we assume to be an incompressible substrate of glacial origin. The stratigraphy does not significantly differ other than an increased amount of silt incorporated into the peat at the top of core FHM-112. Downcore organic content, expressed as percent LOI, ranged from $1.37 \%$ at $22-24 \mathrm{~cm}$ to $51.6 \%$ at $360-362 \mathrm{~cm}$ with an average measured LOI of $56.3 \%$ for the peat unit above the glacial substrate (Figure $7 a)$. 


\subsubsection{Fossil Foraminifera}

Foraminifera were present in FHM-112 at all sampled depths in the peat units (Figure $7 b$ ). Three samples yielded fewer than 40 foraminifera, seven samples yielded 41-99 foraminifera, and 110 samples provided counts greater than 100 individuals. Samples with low counts occurred predominantly near the base of the core from 332-296 $\mathrm{cm}$ and for samples between 236-227 cm. Samples containing fewer than 40 foraminifera were excluded from further analyses because they may be statistically unrepresentative of downcore assemblages with the potential to return an unreliable reconstruction (Kemp and Telford, 2015). The downcore assemblage of foraminifera is comprised of four major species that have an average abundance of $69.3 \%$ (J. macrescens), $13.5 \%$ (T. inflata and S. lobata combined), $12.1 \%$ (T. comprimata), and $4.5 \%$ (M. fusca). Foraminifera are absent in the basal sand unit below $337 \mathrm{~cm}$ with $J$. macrescens occurring immediately at the basal-peat contact. Between $337 \mathrm{~cm}$ and $281 \mathrm{~cm}$, the dominant species was $J$. macrescens (average $86.1 \%$ ). This unit contained two samples with counts fewer than 40 individuals and six samples with counts between 41 and 99 individuals. From $279 \mathrm{~cm}$ to the top of the core, J. macrescens remained the dominant species (average 65.9\%). The average abundance of $T$. inflata and $S$. lobata (13.5\%) notably increases from $74-37 \mathrm{~cm}$ (average 29.6\%). T. comprimata occurs throughout the core (average abundance $12.1 \%$ ) with a noticeable increase at 89-79 cm (average 40.4\%) and 279-239 cm (average $23.6 \%$ ), corresponding with a switch to a light brown peat for the latter and $\mathrm{C}_{3} \delta^{13} \mathrm{C}$ values for the former. $M$. fusca represents a small percent of the fossil assemblage 
(average $4.5 \%$ ), demonstrating a low abundance below $185 \mathrm{~cm}$ (average $<1 \%$ ) with an increase at 140-107 $\mathrm{cm}$ (average 14.3\%) and 34-0 cm (average 15.4\%).

\subsubsection{Bulk Sediment $\delta^{13} C$}

$\delta^{13} \mathrm{C}$ values of downcore bulk sediment ranged from $-13.4 \%$ to $-26.7 \%$ (at base of the core) demonstrating transitions in depositional environments (Figure 7c; see section 4.2 for $\delta^{13} \mathrm{C}$ threshold values). From $350-335 \mathrm{~cm}$, the average $\delta^{13} \mathrm{C}$ value was 23.8\%, which indicates deposition in an environment dominated by $\mathrm{C}_{3}$ plants. From 330 $305 \mathrm{~cm}$, the average $\delta^{13} \mathrm{C}$ value was $-18.2 \%$, which does not indicate deposition dominated by either $\mathrm{C}_{3}$ or $\mathrm{C}_{4}$ plants. From $300-130 \mathrm{~cm}$, the average $\delta^{13} \mathrm{C}$ value was 14.8\%, which indicates deposition in an environment dominated by $\mathrm{C}_{4}$ plants. Within the unit from 300-130, a short interval from $205-200 \mathrm{~cm}$ had an average $\delta^{13} \mathrm{C}$ value of 17.8\%, which does not indicate deposition dominated by either $\mathrm{C}_{3}$ or $\mathrm{C}_{4}$ plants. From 130-105 cm, the average $\delta^{13} \mathrm{C}$ value was $-17.3 \%$, which does not indicate deposition dominated by either $\mathrm{C}_{3}$ or $\mathrm{C}_{4}$ plants. From $110-75 \mathrm{~cm}$, the average $\delta^{13} \mathrm{C}$ value was 21.2\%o, which indicates deposition in an environment dominated by $\mathrm{C}_{3}$ plants. From $65-5$ $\mathrm{cm}$, the average $\delta^{13} \mathrm{C}$ value was $-15.5 \%$, which indicates deposition in an environment dominated by $\mathrm{C}_{4}$ plants. The top of core FHM-112 yields a $\delta^{13} \mathrm{C}$ value of $-17.1 \%$, which does not indicate deposition dominated by either $\mathrm{C}_{3}$ or $\mathrm{C}_{4}$ plants. S. patens, S. alterniflora (short form), and S. virginica were observed at the core location.

\subsection{Chronology for FHM-112}

Thirty radiocarbon dates (Table 1) demonstrate that FHM-112 spans the period since 
1200 BCE. Eight chronohorizons are provided by downcore lead isotope ratios, heavy metal concentrations, and ${ }^{137} \mathrm{Cs}$ activity (Figure 8; values reported in Table 2). The initial peak of ${ }^{206} \mathrm{~Pb} /{ }^{207} \mathrm{~Pb}$ (from $45-48 \mathrm{~cm}$ ) above an average background ratio is interpreted to reflect the maximum production of lead in the Upper Mississippi Valley relative to national U.S. production during the late 1850s (e.g. Lima et al., 2005b). We therefore assigned an age of $1858 \pm 5 \mathrm{CE}$ with a depth uncertainty of $46 \pm 4 \mathrm{~cm}$. The recent minimum of ${ }^{206} \mathrm{~Pb} /{ }^{207} \mathrm{~Pb}$ (from $5-10 \mathrm{~cm}$ ) reflects the introduction of leaded gasoline that had a low signature of $\sim 1.165$ (Hurst, 2000) and was therefore assigned an age of $1965 \pm 5$ CE with a depth uncertainty of $7.5 \pm 2.5 \mathrm{~cm}$. The rise to a recent maximum of ${ }^{206} \mathrm{~Pb} /{ }^{207} \mathrm{~Pb}$ at $4 \mathrm{~cm}$ was interpreted to represent the phasing out of leaded gasoline (e.g. Bollhöfer and Rosman, 2001; Lima et al., 2005b) and was assigned an age of 1980 \pm 5 CE with a depth uncertainty of $4.5 \pm 0.5 \mathrm{~cm}$.

The initial rise of lead (from $42-27 \mathrm{~cm}$ ) above average background values was interpreted to be the result of the onset of production emissions associated with industrialization in New England (e.g. Nixon, 1995). Similarly, the initial rise of mercury, copper, and vanadium above average background values were interpreted to signal the onset of industrial production and emissions. This feature was therefore assigned an age of $1875 \pm 25 \mathrm{CE}$ with a depth uncertainty of $34.5 \pm 7.5 \mathrm{~cm}$. The initial peak of mercury (from 15-22 cm) is interpreted to be a regional signal, identified by Varekamp et al. (2003), of increased mercury deposition in the late 1800s and early 1900s. We therefore assigned this feature an age of $1900 \pm 10 \mathrm{CE}$ with a depth uncertainty of $18.5 \pm 3.5 \mathrm{~cm}$. The most recent and maximum peaks in lead $(134 \mathrm{ppm})$ at $5 \mathrm{~cm}$, mercury $(0.2 \mathrm{ppm})$ at $10 \mathrm{~cm}$, copper (45 ppm) at $5 \mathrm{~cm}$, and vanadium $(65 \mathrm{ppm})$ at $5 \mathrm{~cm}$ were interpreted to represent 
peak industrial emissions immediately prior to the introduction and enforcement of the Clean Air Act. This feature was therefore assigned an age of $1974 \pm 5$ CE with a depth uncertainty of $7 \pm 3 \mathrm{~cm}$. The initial increase in ${ }^{137} \mathrm{Cs}$ activity (from $8-10 \mathrm{~cm}$ ) above average background values was interpreted to be the initial occurrence of ${ }^{137} \mathrm{Cs}$ in the atmosphere due to nuclear weapons testing (e.g. Corbett and Walsh, 2015; Lima et al., 2005a) and was assigned an age of $1954 \pm 2 \mathrm{CE}$ with a depth uncertainty of $10 \pm 2 \mathrm{~cm}$. A peak in ${ }^{137} \mathrm{Cs}$ activity at $5-8 \mathrm{~cm}$ was interpreted to reflect the maximum ${ }^{137} \mathrm{Cs}$ atmospheric fallout following the Limited Test Ban Treaty of 1963 (e.g. Carter and Moghissi, 1977) and was assigned an age of 1963 \pm 1 CE with a depth uncertainty of $6.5 \pm 1.5 \mathrm{~cm}$.

Our final age-depth model, developed for core FHM-112 using the established chronology (Figure 9), provides a resultant average uncertainty $(2 \sigma)$ of \pm 49 years for downcore samples used in the RSL reconstruction. These uncertainties range from \pm 9 years at $10 \mathrm{~cm}$ to \pm 83 years at $337 \mathrm{~cm}$. The age model demonstrates a period of slow sediment deposition of $0.38 \mathrm{~mm} / \mathrm{yr}$ occurring from $235-225 \mathrm{~cm}$ over a period of $\sim 260$ years. This period coincides with samples that contain low counts in foraminifera (25-71 individuals) and is characterized by $J$. macrescens and a decrease in the species $T$. comprimata and combined T. inflata and S. lobata. Another period of slow deposition occurs from $58-36 \mathrm{~cm}$ over a period of $\sim 460$ years, resulting in a depositional rate of 0.48 $\mathrm{mm} / \mathrm{yr}$, and is characterized by the presence of $J$. macrescens, an increase in the species T. inflata and S. lobata, and a decrease in T. comprimata. In contrast, a rather high rate of deposition $(1.9 \mathrm{~mm} / \mathrm{yr})$ occurs from $58-121 \mathrm{~cm}$, spanning 330 years and is characterized by $J$. macrescens and a general pattern of increasing abundances of T. comprimata and $T$. 
inflata and S. lobata moving up core.

\subsection{Reconstructing Paleo Marsh Elevation using a Bayesian Transfer Function}

We applied the Bayesian Transfer Function of Kemp et al. (2017a) to 117

downcore samples of foraminifera and produced PME estimates with a $2 \sigma$ uncertainty for each sample (PME estimates, vertical errors, and assigned priors of each sample are provided in Table 3). PME estimates ranged from $-0.20 \mathrm{~m}$ MHHW to $0.29 \mathrm{~m}$ MHHW at

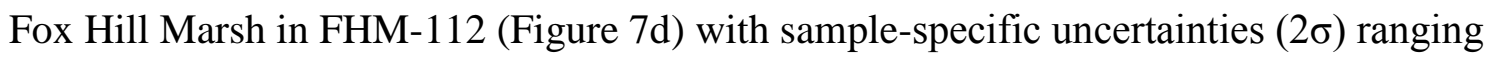
from $\pm 0.03 \mathrm{~m}$ to $\pm 0.34 \mathrm{~m}$, equivalent to $\pm 2.5 \%$ and $\pm 29 \%$ of the great diurnal tidal range at Fox Hill Marsh. Samples at the base of the core yielded PME estimates close to the HOF and are dominated by J. macrescens. PME estimates for samples between 332-305 $\mathrm{cm}$ range from $-0.04-0.24 \mathrm{~m}$ MHHW with an average uncertainty of $\pm 0.22 \mathrm{~m}$. This unit contains a high abundance of $J$. macrescens with the presence of $T$. comprimata and corresponds with the unit in the core that consistently contained few foraminifera (Figure 7b). Samples from $299-113 \mathrm{~cm}$ produced an average PME estimate of $-0.08 \mathrm{~m}$ MHHW with uncertainties ranging from $\pm 0.08-0.33 \mathrm{~m}$ and are associated with a variety of foraminiferal species but dominated by J. macrescens. PME estimates from 110-77 cm range from $0.02-0.08 \mathrm{~m}$ MHHW with a notable increase in $T$. comprimata observed in this interval. The $\delta^{13} \mathrm{C}$ provides additional constraints for these samples, reducing vertical uncertainty to an average of $\pm 0.05 \mathrm{~m}$. Samples from $74-0 \mathrm{~cm}$ produced PME estimates averaging $-0.03 \pm 0.19 \mathrm{~m}$ MHHW.

To identify fossil samples lacking a modern analogue in the Kemp et al. (2017) modern training set, we measured dissimilarity between core and modern samples using 
the squared chi-square distance metric. The minimum calculated dissimilarity showed that all core samples fell within the 20th percentile of distance calculated among all possible pairs of samples in the modern training set. Therefore, all core samples have an appropriate modern analog and were retained in our RSL reconstruction (Figure 7e).

\subsection{Relative Sea-Level Trends}

We reconstructed RSL by subtracting the estimated PME from the measured altitude of each sample in FHM-112 (Figure 10a). The age of each sample with uncertainty (all uncertainties reported hereafter are the $95 \%$ credible interval) was estimated from the age-depth model. Comparison of regional trends (Figure 2) demonstrates that the Newport tide gauge is representative of regional trends in RSL. The decadal-averaged tide-gauge data lies within the uncertainties of the proxy-based reconstruction and it is therefore reasonable to combine them to provide a RSL history for Fox Hill Marsh. Applying the EIV-IGP model to the combined (proxy and instrumental) reconstruction shows that RSL rose from $-3.92 \pm 0.09 \mathrm{~m}$ at approximately $1250 \mathrm{BCE}$ to $0.00 \pm 0.03 \mathrm{~m}$ at present (2014 CE; Figure $10 \mathrm{~b}$ ) with fluctuating rates of change (Figure 10c).

The rate of RSL rise fell from $1.90 \pm 0.38 \mathrm{~mm} / \mathrm{yr}$ at $1100 \mathrm{BCE}$ to a minimum $(0.55 \pm 0.27 \mathrm{~mm} / \mathrm{yr})$ at $250 \mathrm{BCE}$. Starting at $250 \mathrm{BCE}$, the rate of RSL rise increased to reach a maximum rate of $1.33 \pm 0.3 \mathrm{~mm} / \mathrm{yr}$ at $250 \mathrm{CE}$ and proceeded to fall to a minimum rate of $0.57 \pm 0.24 \mathrm{~mm} / \mathrm{yr}$ at $750 \mathrm{CE}$. From $750 \mathrm{CE}$, the rate of RSL increased again, reaching a rate of $1.78 \pm 0.25 \mathrm{~mm} / \mathrm{yr}$ at $1200 \mathrm{CE}$, after which it fell to the most recent minimum rate of $0.37 \pm 0.25 \mathrm{~mm} / \mathrm{yr}$ at $1600 \mathrm{CE}$. The rate of RSL accelerated continuously 
following $1600 \mathrm{CE}$ to reach a current $(2014 \mathrm{CE})$ rate of $3.71 \pm 0.76 \mathrm{~mm} / \mathrm{yr}$. Change point analysis was performed on the combined proxy and instrumental dataset to determine significant periods of RSL change. Change point analysis recognized three persistent phases of RSL change (with a 95\% credible interval) during the $\sim 3,250$-year period of reconstructed RSL (Figure 10b). The first change point at 898-686 BCE is associated with a decrease in the rate of RSL rise from $1.93 \pm 0.39 \mathrm{~mm} / \mathrm{yr}$ to $0.97 \pm 0.02 \mathrm{~mm} / \mathrm{yr}$. The second change point is the onset of modern rates of RSL rise $(2.88 \pm 0.97 \mathrm{~mm} / \mathrm{yr})$ between 1786 to $1907 \mathrm{CE}$. 


\section{CHAPTER 5}

\section{Discussion}

\subsection{Distribution of Modern Salt-Marsh Foraminifera}

The observed relationship between foraminifera and tidal elevation at Fox Hill Marsh is broadly similar to other sites in New England. The unvegetated tidal flat and low salt marsh from $-0.39 \mathrm{~m}$ MHHW to $-0.15 \mathrm{~m}$ MHHW is represented by five samples that are dominated by $M$. fusca, which is typical of the distributions observed at other sites in southern New England (Edwards et al., 2004; Wright et al., 2011). Above -0.15 m MHHW, M. fusca abundance decreases and Ammobaculites spp. and T. comprimata abundance begins to increase up to $-0.08 \mathrm{~m}$ MHHW. M. fusca and Ammobaculites spp. are not present above MHW (-0.08 m MHHW).

The high marsh from $-0.14 \mathrm{~m}$ MHHW to $0.11 \mathrm{~m}$ MHHW is represented by 13 samples that are dominated by J. macrescens and T. comprimata. J. macrescens demonstrates an increasing abundance up to the highest sampled elevation at $0.11 \mathrm{~m}$ MHHW consisting of 55\% of that sample, demonstrating a typical southern New England distribution (Edwards et al., 2004; Wright et al., 2011). Haplophragmoides spp. abundance increases to $18 \%$ at MHW and continues to increase up to the highest sampled elevation, consisting of $28 \%$ of that sample. Maximum abundances of $T$. comprimata and T. inflata and S. lobata in the high marsh are near MHW and decrease up to the highest sampled elevation at $0.11 \mathrm{~m} \mathrm{MHHW,} \mathrm{consisting} \mathrm{of} 11 \%$ and $2 \%$, respectively, of that assemblage.

J. macrescens individuals are present in every sample at Fox Hill Marsh and characterize the high marsh assemblage, which is typical at other southern New England 
sites (Edwards et al., 2004; Gehrels and van de Plassche, 1999; Wright et al., 2011). However, a large abundance of $J$. macrescens is also found in the low-marsh assemblage (>20\% abundance), which is not characteristic of foraminiferal distributions at other sites in southern New England (Edwards et al., 2004; Wright et al., 2011). Similarly, T. inflata and S. lobata represent a higher percent of the low-marsh assemblage (up to 25\%) than is seen at other southern New England sites, which show a decrease in $T$. inflata and $S$. lobata abundance below MHW (Edwards et al., 2004). The peak abundance of $T$. comprimata is at MHW and demonstrates a decreasing abundance above MHHW, which is demonstrated at other southern New England sites (Edwards et al. 2004b; Gehrels and van de Plassche, 1999; Wright et al., 2011). Similar to distributions observed elsewhere, Haplophragmoides spp. are abundant in the high marsh above MHW (Gehrels and van de Plassche, 1999; Edwards et al., 2004) and are interpreted to represent brackish conditions at high elevations in transect B-B' (Edwards et al., 2004).

The vertical distribution of our modern dataset does not capture the HOF as every sample contained abundant foraminifera. The high abundances of J. macrescens and $T$. inflata and S. lobata below MHW may be the result of sampling sediment slumping from the high-marsh platform that forms an erosive cliff at the edge of the high marsh or the sampling of high marsh peat that lies just below the surface of the tidal flat sediments. The restricted circulation of the pond may result in eroded foraminiferal tests being incorporated into the tidal flat sediments rather than being washed away. Similar issues have been highlighted from a site in southern Oregon (Milker et al., 2016). Therefore, in our modern dataset elevations below MHW are best determined by the presence of $M$. fusca and Ammobaculites spp. as an indicator. 


\subsection{Estimation and Removal of the Glacial Isostatic Adjustment Contribution}

On the US Atlantic coast, the redistribution of mantle material following the retreat and eventual demise of the Laurentide Ice Sheet results in spatially variable land subsidence due to forebulge collapse as the solid earth returns towards isostatic equilibrium (e.g. Barnhardt et al., 1995; Lambeck and Chappel, 2001; Peltier, 2004). To allow for comparison of climate-driven sea-level changes we must remove the contribution of GIA plus any other sources of vertical land motion from RSL records. Estimates of GIA and its contribution to RSL change may come from multiple sources including observational data such as GPS measurements (e.g. Karegar et al., 2016; Sella et al., 2007), RSL reconstructions from basal-peats (e.g. Engelhart et al., 2009), and predictions from earth-ice models (e.g. Love et al., 2016; Peltier et al., 2015). All these methods demonstrate similar spatial patterns in GIA due to an ongoing response to deglaciation, although disagreements still remain between models and observational data (e.g., Engelhart et al., 2011). GPS measurements estimate a GIA rate of $0.9 \pm 0.2 \mathrm{~mm} / \mathrm{yr}$ in southern Rhode Island (Karegar et al., 2016), basal peat reconstructions estimate rates of GIA between $1.1 \pm 0.1$ and $1.2 \pm 0.2 \mathrm{~mm} / \mathrm{yr}$ in southern Connecticut and Massachusetts (Engelhart et al., 2009), and earth-ice model ICE-6G_C (VM5a) predicts a GIA rate of $1.3 \mathrm{~mm} / \mathrm{yr}$ at Newport, Rhode Island (Peltier et al., 2015).

Using a GPS record located $\sim 11 \mathrm{~km}$ from our site (GPS site code URIL; Karegar et al., 2016), we removed $0.9 \mathrm{~mm} / \mathrm{yr}$ (with no error associated with it) from the Fox Hill Marsh RSL reconstruction using the EIV-IGP model, accounting for uncertainties given by the GIA correction (Cahill et al., 2015) to produce a detrended sea-level 
reconstruction with uncertainty (reported hereafter as the $95 \%$ credible interval). We assumed a constant GIA rate of $0.9 \mathrm{~mm} / \mathrm{yr}$ for the time span of our reconstruction. This assumption is reasonable because the half-life of GIA results in exponentially decreasing rates of subsidence (or uplift) that we treat as linear over short time frames (e.g. Kemp et al., 2015). The detrended sea-level reconstruction produced from Fox Hill Marsh captures multiple departures from stable sea level ( 0 mm/yr; Figure $11 \mathrm{~d}$ ) over our $\sim 3,300$-year record.

Detrended sea level rose from $-0.97 \pm 0.10 \mathrm{~m}$ at approximately $1250 \mathrm{BCE}$ to reach $-0.43 \pm 0.04 \mathrm{~m}$ at $500 \mathrm{BCE}$ (Figure 11a; 11d). This rise in sea level was associated with a rate of rise between $0.91 \pm 1.23 \mathrm{~mm} / \mathrm{yr}$ and $0.98 \pm 0.40 \mathrm{~mm} / \mathrm{yr}$ from approximately 1250 BCE-1100 BCE, after which the rate of sea-level rise decreased until it fell below 0 $\mathrm{mm} / \mathrm{yr}$ to reach a negative rate of $-0.33 \pm 0.25 \mathrm{~mm} / \mathrm{yr}$ at $250 \mathrm{BCE}$. Negative rates of sealevel change resulted in a $\sim 500$-year sea-level fall from $-0.43 \pm 0.04 \mathrm{~m}$ at $500 \mathrm{BCE}$ to $-0.53 \pm 0.05 \mathrm{~m}$ at $0 \mathrm{CE}$. Following $250 \mathrm{BCE}$, the rate of sea-level change increased above $0 \mathrm{~mm} / \mathrm{yr}$ to reach a positive rate of $0.43 \pm 0.28 \mathrm{~mm} / \mathrm{yr}$ at $250 \mathrm{CE}$. This resulted in a $\sim 500$ year sea-level rise from $-0.53 \pm 0.05 \mathrm{~m}$ at $0 \mathrm{CE}$ to $-0.39 \pm 0.05 \mathrm{~m}$ at $500 \mathrm{CE}$. Following 500 $\mathrm{CE}$, the rate of sea level subsequently fell below $0 \mathrm{~mm} / \mathrm{yr}$ to reach a negative rate of $-0.31 \pm 0.25 \mathrm{~mm} / \mathrm{yr}$ at $700 \mathrm{CE}$, resulting in a 400 -year-long sea-level fall from $-0.39 \pm 0.05 \mathrm{~m}$ at $500 \mathrm{CE}$ to. The rate of sea-level change then increased above $0 \mathrm{~mm} / \mathrm{yr}$ to reach a positive rate of $0.86 \pm 0.24 \mathrm{~mm} / \mathrm{yr}$ at $1200 \mathrm{CE}$. The rate increase during this time resulted in a rise of sea level from $-0.47 \pm 0.04 \mathrm{~m}$ at $900 \mathrm{CE}$ to $-0.20 \pm 0.06 \mathrm{~m}$ at $1450 \mathrm{CE}$. Following $1200 \mathrm{CE}$, the rate of sea level decreased, falling below $0 \mathrm{~mm} / \mathrm{yr}$ to reach the most recent and lowest minimum rate of $-0.49 \pm 0.26 \mathrm{~mm} / \mathrm{yr}$ at $1600 \mathrm{CE}$. Negative rates of 
sea-level change during this time resulted in the most recent sea-level fall, from $-0.20 \pm 0.06 \mathrm{~m}$ at $1450 \mathrm{CE}$ to a minimum of $-0.31 \pm 0.06 \mathrm{~m}$ at $1750 \mathrm{CE}$. Following 1750 $\mathrm{CE}$, the rate of sea-level change increased above $0 \mathrm{~mm} / \mathrm{yr}$ to reach a current (2014 CE) rate of $2.74 \pm 0.79 \mathrm{~mm} / \mathrm{yr}$ and sea level at $0 \pm 0.03 \mathrm{~m}$ at present $(2014 \mathrm{CE})$. Our detrended sea-level reconstruction shows that the modern rate of sea-level rise is the fastest, century-scale rate over the $\sim 3,300$-year span of our record. This is consistent with a global compilation that identified current rates of sea-level rise are higher now than at any time during the past 2,800 years (Kopp et al., 2016).

\subsection{Sea-Level Trends in New England}

Kemp et al. (2015) produced a Common Era RSL reconstruction from East River Marsh, Connecticut (Figure 1a) using basal peat overlying bedrock. This data covers the period $200 \mathrm{BCE}$ to $2014 \mathrm{CE}$ and the use of basal samples negates the contribution of compaction to the record. Kemp et al. (2015) reconstructed a relatively stable rate of change from $200 \mathrm{BCE}$ to $600 \mathrm{CE}$, never falling below a rate of $-1.0 \mathrm{~mm} / \mathrm{yr}$ and never rising above a rate of $0.09 \mathrm{~mm} / \mathrm{yr}$, with an average uncertainty (95\% credible interval) of $\pm 0.23 \mathrm{~mm} / \mathrm{yr}$ during this period (Figure 11e). This contrasts with our record from Fox Hill Marsh during which time sea level in Rhode Island exhibited both positive and negative oscillations from stability. Kemp et al. (2015) identified a slight sea-level rise of $\sim 0.18 \mathrm{~mm} / \mathrm{yr}$ from $600-1000 \mathrm{CE}$ and reported a minimum rate of $-0.42 \mathrm{~mm} / \mathrm{yr}(-0.22$ to $-0.62 \mathrm{~mm} / \mathrm{yr}$; $95 \%$ credible interval) at $\sim 1400 \mathrm{CE}$ and a subsequent continuous increase to reach a rate of $2.38 \mathrm{~mm} / \mathrm{yr}(2.16-2.62 \mathrm{~mm} / \mathrm{yr} ; 95 \%$ credible interval $)$ at $2014 \mathrm{CE}$. These oscillations were associated with sea-level response to the Medieval Climate Anomaly and Little Ice Age, respectively. This trend is comparable to the sea-level trends 
reconstructed in Rhode Island during this time (i.e. a fall to a minimum and continuous rate increase to present). However, the timings of these rate changes differs between records as they occur earlier in the Connecticut record. Further, the magnitude of these oscillations from stability are larger in Rhode Island than at Connecticut and Rhode Island exhibits two more phases of sea-level oscillations than Connecticut, which extend prior to the Common Era (Figure 11). This disagreement in timing between the records suggests that the current Connecticut record (Kemp et al., 2015) is not representative of the entire southern New England coast.

Kemp et al. (2017a) produced a RSL reconstruction from Pelham Bay, New York (Figure 1a) using a continuous core $(\sim 1.6 \mathrm{~m})$ of salt-marsh peat. To facilitate comparison with the records from Connecticut and Rhode Island, we applied the EIV-IGP model to the RSL dataset of Kemp et al. (2017a), removing a GIA contribution of $1.1 \mathrm{~mm} / \mathrm{yr}$ (e.g., Engelhart et al., 2009). The detrended sea-level data covers the period 550 CE to 2000 $\mathrm{CE}$. This record shows a decrease in the rate of rise from $-0.54 \pm 1.41 \mathrm{~mm} / \mathrm{yr}$ to $-0.73 \pm 0.42 \mathrm{~mm} / \mathrm{yr}$ at $550-800 \mathrm{CE}$ and a subsequent increase to a rate of $0.28 \pm 0.32$ $\mathrm{mm} / \mathrm{yr}$ at $1450 \mathrm{CE}$. This trend is comparable to the rates of sea-level change estimated for Rhode Island during this time (i.e. a fall and subsequent rise). These trends diverge, however, and the rate of sea-level change in New York shows stability (average $0.25 \pm 0.31 \mathrm{~mm} / \mathrm{yr}$ ) from $1350-1700 \mathrm{CE}$, whereas sea level in Rhode Island proceeded to fall to a minimum at $1600 \mathrm{CE}$. The rate of sea level change in New York then rose to reach a rate of $1.60 \pm 0.76 \mathrm{~mm} / \mathrm{yr}$ at $2000 \mathrm{CE}$ (Figure 11f).

The detrended sea-level record from Fox Hill Marsh (Figure 11a) shows similarities and differences in timing from the existing records in Connecticut (Kemp et 
al., 2015; Figure 11b) and New York (Kemp et al., 2017a; Figure 11c). This result is somewhat surprising given the sites are separated by $\sim 200 \mathrm{~km}$. Our results support previous conclusions from the U.S. Atlantic coast that sea-level oscillations exist that may be correlated with known climate anomalies (e.g. Kemp et al., 2011, 2013, 2015). Although the new Rhode Island sea-level reconstruction varies from the records discussed here, all records consistently demonstrate that current rates of sea-level rise are greater than any previous rates estimated for the span of each reconstruction. This remains a consistent conclusion in both regional (e.g. Kemp et al., 2017b) and global RSL studies (e.g. Church et al., 2008; Kopp et al., 2016).

\subsection{Potential Influence on the Relative Sea-Level Reconstruction}

The variations between three records located within $\sim 200 \mathrm{~km}$ of each other in southern New England and the northern mid-Atlantic necessitates consideration of the possible processes that may be driving these differences.

\subsubsection{Artifacts of the RSL method}

\subsubsection{Age Model Choice and Density of Radiocarbon Dates}

Although the chronology developed for this study, Kemp et al. (2015), and Kemp et al. (2017a) provide downcore samples with an average $95 \%$ credible interval of \pm 50 years, the density of radiocarbon dates used to constrain each chronology varies, resulting in different age-depth models that may miss important changes in sedimentation rates which could lead to timings in sea level that are offset between reconstructions (e.g., Wright et al., 2017). The Rhode Island chronology consists of 30 radiocarbon dates from $337-43 \mathrm{~cm}$, resulting in age stacking and radiocarbon dates spaced every $4-21 \mathrm{~cm}$. In 
comparison, the chronology developed by Kemp et al. (2015) is composed of 15 radiocarbon dates which are spaced every $7-35 \mathrm{~cm}$. Similarly, the reconstruction of Kemp et al. (2017a) is composed of ten radiocarbon dates that are spaced every 6-18 cm. These differences in density of radiocarbon ages discussed here may be causing the differences observed between the reconstructions.

For example, there are noticeable differences in the density of radiocarbon dates in the chronology at times sea level is oscillating in the Connecticut reconstruction and the Rhode Island reconstruction. The reconstruction in Connecticut shows oscillations from $800-1600$ CE (Figure 11e) and is constrained by four radiocarbon dates. The Rhode Island chronology is constrained by nine radiocarbon dates for this period, with stacking of three radiocarbon dates from 1000-1300 CE (Figure 9) and is associated with a positive fluctuation in sea level (Figure 11d), whereas the Connecticut reconstruction shows a negative fluctuation in sea level during that time. The age stacking in the Rhode Island chronology may be shifting the reconstruction to offset times of sea-level rise and fall between Rhode Island and Connecticut.

The most recent oscillations in Rhode Island are captured from 1000-1800 CE (Figure 11d). The Rhode Island chronology during this time is constrained by eight radiocarbon dates, with the aforementioned stacking from 1000-1300 CE (Figure 9), while the Connecticut chronology is constrained by five radiocarbon dates during this period. The offsets in the sea-level oscillations in each reconstruction is possibly explained by these differences. Similarly, the Rhode Island reconstruction shows a phase of oscillations from 0-1000 CE that is not captured in the Connecticut reconstruction (Figure 11d; 11e). The Rhode Island chronology is constrained by ten radiocarbon dates 
for this period with stacking of three radiocarbon dates from 0-300 CE (Figure 9) and a positive sea-level fluctuation is observed in the Rhode Island reconstruction during this time. The Connecticut chronology, however, is constrained by eight radiocarbon dates over 0-1000 CE and has stacking of three radiocarbon dates from 500-600 CE, which is where a positive fluctuation in sea level occurs in Connecticut opposed to Rhode Island (Figure 11).

The third phase of sea-level oscillations in Rhode Island expand beyond the length of the Connecticut reconstruction and are captured from $500 \mathrm{BCE}-0 \mathrm{CE}$. The chronology is constrained by five radiocarbon dates during the period with stacking of three radiocarbon dates from approximately 400-200 BCE (Figure 9), and is associated with the positive fluctuation in sea-level. Positive fluctuations in sea level are occurring where there is age stacking in the chronology. For this reason, it is apparent that the Rhode Island age-depth model is capturing small sedimentation changes resulting in a reconstruction that is primarily driven by the chronology, as opposed to the Connecticut record which is driven by foraminiferal distributions. For instance, the Connecticut reconstruction displays a negative fluctuation in sea level from approximately 1000-1500 CE (Figure 11e). The Connecticut age-depth model is constrained by three radiocarbon dates for this time period and shows linear sedimentation, which suggests that the foraminiferal distributions are driving interpretations of the fall in sea level.

Simple interpolation of radiocarbon data has the potential to create false rate changes that mirror the radiocarbon calibration curve (Gehrels et al., 2005). However, it has been shown that age-depth models, including the model used in this study (Bchron; Haslett and Parnell, 2008), are not affected in this way when a well-dated sequence, like 
FHM-112, is used (Wright et al., 2017). Furthermore, a chronology developed using multiple dating methods (e.g. radiocarbon and pollution markers) does not produce marked rate changes but instead produces wider confidence intervals. The Rhode Island RSL reconstruction is primarily driven by the chronology and our choice of age-model is most likely not producing spurious oscillations in RSL. This suggests that the differences between the reconstructions may be driven by the density of chronological markers in FHM-112 that identify oscillations in sedimentation rates over periods of less than $\sim 300$ years that may be missed by a coarser-resolution dating approach that trends towards linear sedimentation rates.

\subsubsection{Resolution}

A further possible explanation for the differences between the reconstructions is the average uncertainty of PME estimates used in the reconstruction, because reconstructions at a higher resolution can identify smaller changes of RSL. It is possible that the different trends observed between each RSL record are due to the high-resolution reconstruction we produced and the low uncertainties of our PME estimates. For instance, Kemp et al. (2015) estimated PME at $1 \sigma$ using a different transfer function approach (weighted-averaging with inverse deshrinking) where estimates could not be constrained by $\delta^{13} \mathrm{C}$ values because most downcore samples had intermediate $\delta^{13} \mathrm{C}$ signals that could not distinguish between deposition above or below MHHW. The reported samplespecific PME uncertainties at $1 \sigma$ ranged from $\pm 0.16-0.17 \mathrm{~m}$, approximately double the sample-specific uncertainties from our reconstruction (average PME uncertainty of \pm 0.17 $\mathrm{m}$; range from \pm 0.03 to $0.34 \mathrm{~m}$ ) that represent $2 \sigma$ confidence intervals. The resolution of 
our record may have allowed us to reconstruct smaller trends in sea level, which could account for the differences between the Rhode Island and Connecticut reconstructions.

\subsubsection{Physical Processes}

If the cyclical fluctuations observed in our reconstruction are not artifacts of the RSL reconstruction methodology, then the changes that we capture must be due to regional or local processes that oscillate over centennial time scales. The reconstructions we compared are detrended sea-level records corrected for vertical land movement. Therefore, GIA-related subsidence is not driving the differences seen between them. Global signals such as the addition of ice equivalent meltwater input are considered unlikely influences on the differences between the three records due to their close proximity. Here we explore regional effects of the Atlantic Meridional Overturning Circulation (AMOC) and local signals that could be captured in our reconstruction.

\subsubsection{Regional Signal - Atlantic Meridional Overturning Circulation}

It has been shown that RSL changes along the east coast of the U.S. are highly influenced by AMOC. This results in spatial variations of rates of RSL rise along the coast (Ezer, 2013), most notably within our study area in the mid-Atlantic and New England regions (Sallenger et al., 2012). RSL reconstructions along the U.S. east coast show spatial variability which is attributed to dynamic oceanic and/or atmospheric circulation related to North Atlantic Oscillation (NAO) and AMOC changes but limitations and inconsistencies between climate models result in caveats of this interpretation and it remains to be clear how significant AMOC is on driving RSL 
changes along the east coast over multi-decadal scales (see Kemp et al., 2017a). Models project that sea-level changes related to AMOC demonstrate regional signals and we would, therefore, expect the RSL reconstructions in southern New England to capture identical oscillations during the same time periods if these were in fact related to AMOC changes. Further, proxy evidence of changes in the strength of the Gulf Stream (Lund et al., 2006) produce regional signals of $1.5-6 \mathrm{~cm}$ of sea-level rise; too small for this to be identified between reconstructions.

\subsubsection{Local Signals}

Local influences that drive changes in RSL range from short-lived processes (e.g. storm surge) and long-lived processes such as, underground fluid and gas extraction (e.g. Kolker et al., 2011), wind patterns (e.g. Woodworth et al., 2014), tidal-range changes (e.g. Nikitina et al., 2015), and sediment compaction (e.g. Törnqvist et al., 2008). Here we explore three local processes that could have influenced sea-level change in Narragansett Bay: wind patterns, tidal-range change, and sediment compaction.

\subsection{Wind Driven RSL Changes}

Atmospheric drivers largely affect RSL on a local scale because changing wind patterns, accompanied by atmospheric pressure changes, can affect upwelling/downwelling regimes and/or drive currents towards or away from the coast

(e.g. Kolker et al., 2011). In Narragansett Bay, current velocities are strongly affected by wind forcing that results in significant water exchange between the west and east passages of the bay (Gordon and Spaulding, 1987; Weisberg and Sturges, 1976). 
Additionally, wind forcing influences water exchange between Narragansett Bay and adjacent shelf waters as prevailing winds build shelf water at the mouth of the bay, resulting in pulses of inflow (through the east passage) and outflow (through the west passage; Pfeiffer-Herbert et al., 2015). Although winds drive currents into and between the east and west passages of Narragansett Bay, we cannot conclude that wind forcing is elevating sea-level in the Bay compared to the other sites. If sites in Narragansett Bay were affected by wind stress more so than sites in Long Island Sound, then we would expect to see these differences reflected in regional tide-gauge measurements, which should show RSL differences between tide gauges in Narragansett Bay and Long Island Sound (Figure 2).

\subsection{Tidal-Range Change}

Tidal-range changes are commonly assumed to be minimal over the late Holocene (e.g., Hill et al., 2011). However, recent work from high-resolution models has demonstrated that tidal range can change enough to influence RSL reconstructions during this time (e.g., Hall et al., 2013; Kemp et al. 2017a; 2017b). Using a dataset of basal peat RSL indicators from the Delaware estuary, Hall et al. (2013) and Nikitina et al. (2015) demonstrated that failing to account for changes in tidal range resulted in an overestimation of the rate of late Holocene RSL rise in the upper portion of the Delaware estuary. However, sites in the lower Delaware estuary, similar to Fox Hill Marsh, were largely unaffected.

The effect of tidal-range changes on similar high-resolution RSL reconstructions to those presented here have been investigated in Long Island Sound (Kemp et al., 2017a) 
and North Carolina (Kemp et al., 2017b). Kemp et al. (2017a) modeled changes in tidal range by adjusting water depths in Long Island Sound and demonstrated that the effect of tidal range change in Long Island Sound increases from west to east, with minimal impact on the New York reconstruction (Kemp et al., 2017a) but potential to modify the Connecticut record (Kemp et al., 2015). A $2.5 \mathrm{~m}$ change in water depth results in a $\sim 15 \%$ decrease in great diurnal tidal range at New Haven. A strong relationship is observed between water depth and tidal range that would result in variable tidal range due to oscillations in RSL. However, it is not apparent that changes in tidal range could also affect the difference in the timing of oscillations seen between the Rhode Island and Connecticut records. Further expansion of the tidal modeling results from this study would provide an opportunity to further test the influence in Narragansett Bay.

The possibility of inlet widening or narrowing at Fox Hill Marsh exists, which could result in enhanced or restricted tidal range at the site, impact our estimates of PME and, therefore, cause our RSL reconstruction to deviate from the true value. Aerial photography of the site since 1938 shows variations in the shape and position of the inlet but agreement between our proxy record and the tide gauge record suggests this contribution is likely within our error terms. A further possibility would be complete inlet closure at Fox Hill Marsh, which would cut off tidal flow into the site and result in standing water and reduced sedimentation. However, this mechanism is not likely responsible for the fluctuations in our reconstruction because we would expect to be able to identify such persistent (200 to 300 years) changes in downcore foraminiferal distributions to reflect this throughout the sequence. However, instead we identify a consistent assemblage with high-marsh species such as J. macrescens and T. comprimata. 


\subsection{Sediment Compaction}

Continuous cores of salt marsh peat may be subject to sediment compaction due to compression and biodegradation of material. It has previously been demonstrated that sediment compaction can result in the overestimation of RSL trends by $0.1-0.4 \mathrm{~mm} / \mathrm{yr}$ (e.g., Brain et al., 2015; Horton and Shennan, 2009). Given that the Connecticut record is obtained from compaction-free basal peats, compared to the continuous core record in Rhode Island and New York, we must consider the effect of sediment compaction on the reconstructions. Although the cores in New York and Rhode Island are continuous cores of salt-marsh peat, compaction is likely small because the peat is not overlain by heavy layers of clay or sand and has remained waterlogged since deposition (Brain et al., 2015). Recent work comparing the basal-peat record in Connecticut to a continuous core at the same site has demonstrated that the decompaction model of Brain et al (2015) may underestimate compaction, particularly during past warm periods (Brain et al., 2017). However, even if this is the case for Fox Hill Marsh, compaction would cause a general overestimate in rates of rise and cannot induce oscillations in RSL (Brain et al., 2015). Current compaction models suggest that the influence of compaction is highest in the middle of the core, decreasing towards the top and base. Therefore, we conclude that compaction is not causing the long-lived and cyclical sea-level fluctuations observed in our reconstruction. 


\section{CHAPTER 6}

\section{Conclusions}

To investigate whether RSL in southern New England demonstrates spatial variability over scales of 10 s to 100 s of $\mathrm{km}$, we produced a new high-resolution RSL reconstruction in lower Narragansett Bay, Rhode Island spanning 3,300 years. We sampled foraminifera and bulk-sediment from a dated $\sim 3.3 \mathrm{~m}$ core of salt-marsh peat and developed a composite chronology using 30 radiocarbon dates and pollution markers of known age. We used a previously established, regional-scale training set of modern foraminifera (Kemp et al., 2015) and applied a previously established Bayesian transfer function to estimate PME constrained by downcore $\delta^{13} \mathrm{C}$ values of bulk-sediment. We combined our proxy record with a tide gauge record from Newport, RI that covers the period from 1931 to $2016 \mathrm{CE}$ and analyzed the combined reconstructions with an EIVIGP model that showed RSL rose from $-3.92 \pm 0.09 \mathrm{~m}$ at $1250 \mathrm{BCE}$ to reach current RSL. We removed the predominantly GIA-driven background rates of rise $(0.9 \mathrm{~mm} / \mathrm{yr})$ from the RSL reconstruction using the EIV-IGP method.

By comparing our new record to other GIA-corrected sea-level reconstructions from the northern mid-Atlantic (Kemp et al. 2017a) and southern New England (Kemp et al. 2015), we show that while all sites demonstrate oscillations that have been hypothesized to be due to the Medieval Climate Anomaly and Little Ice Age. However, the timings vary between these closely-spaced sites. Further, the rate of sea-level change has oscillated in Rhode Island at a higher magnitude and more often than in the Connecticut and New York record. Our reconstruction also shows evidence of these oscillations spanning 1,300 years before the Common Era, providing additional 
information over previous regional records that are limited to the Common Era (Kemp et al., 2015; 2017a). The newly captured RSL oscillations prior to the Common Era never exceed modern rates of rise. It is apparent that although RSL trends throughout the Common Era can differ on a smaller spatial scale than previously thought (Kemp et al., 2017b), the most recent acceleration in sea-level rise that poses threats to modern-day coastal infrastructure and communities (e.g. Lin et al., 2016; Neumann et al., 2015; Reed et al., 2015) is consistent among all high-resolution RSL records on the US Atlantic and Gulf coastlines (Gerlach et al., 2017; Kemp et al., 2013b; 2014; 2015; 2017a; 2017b) and indeed, around the world (e.g. Gehrels and Woodworth, 2013; Gehrels et al., 2008; Kemp et al., 2011; Kopp et al., 2016).

After exploring possible reasons for differences between regional records prior to the onset of modern RSL rise, we conclude that the spatial variability observed between Rhode Island and the other sites is a possible result of the high density of radiocarbon dates used to develop our chronology and/or the increased vertical resolution of our reconstruction. Until comparable reconstructions are produced in southern New England, we cannot attribute differences among the records to any one regional or local process. Best practices for future high-resolution RSL reconstructions should include: 1) developing age-depth models that use radiocarbon dates sampled at intervals aimed to reduce model interpolation between dated samples to less than 100 years. A more informed age-depth model could maximize the likelihood of capturing small changes in sedimentation rates missed by current radiocarbon sampling standards; and 2) use a methodology (e.g. Bayesian transfer function) that incorporates multiple lines of evidence where appropriate and available (e.g. bulk sediment $\delta^{13} \mathrm{C}$, diatom assemblages, pollen, 
total organic carbon; e.g. Kemp et al., 2013) to reduce vertical uncertainty. This strategy may aid in reconstructing small-scale (decadal to centennial) RSL trends previously unobtainable using a single-proxy approach (e.g. Kemp et al., 2015). 


\section{APPENDIX}
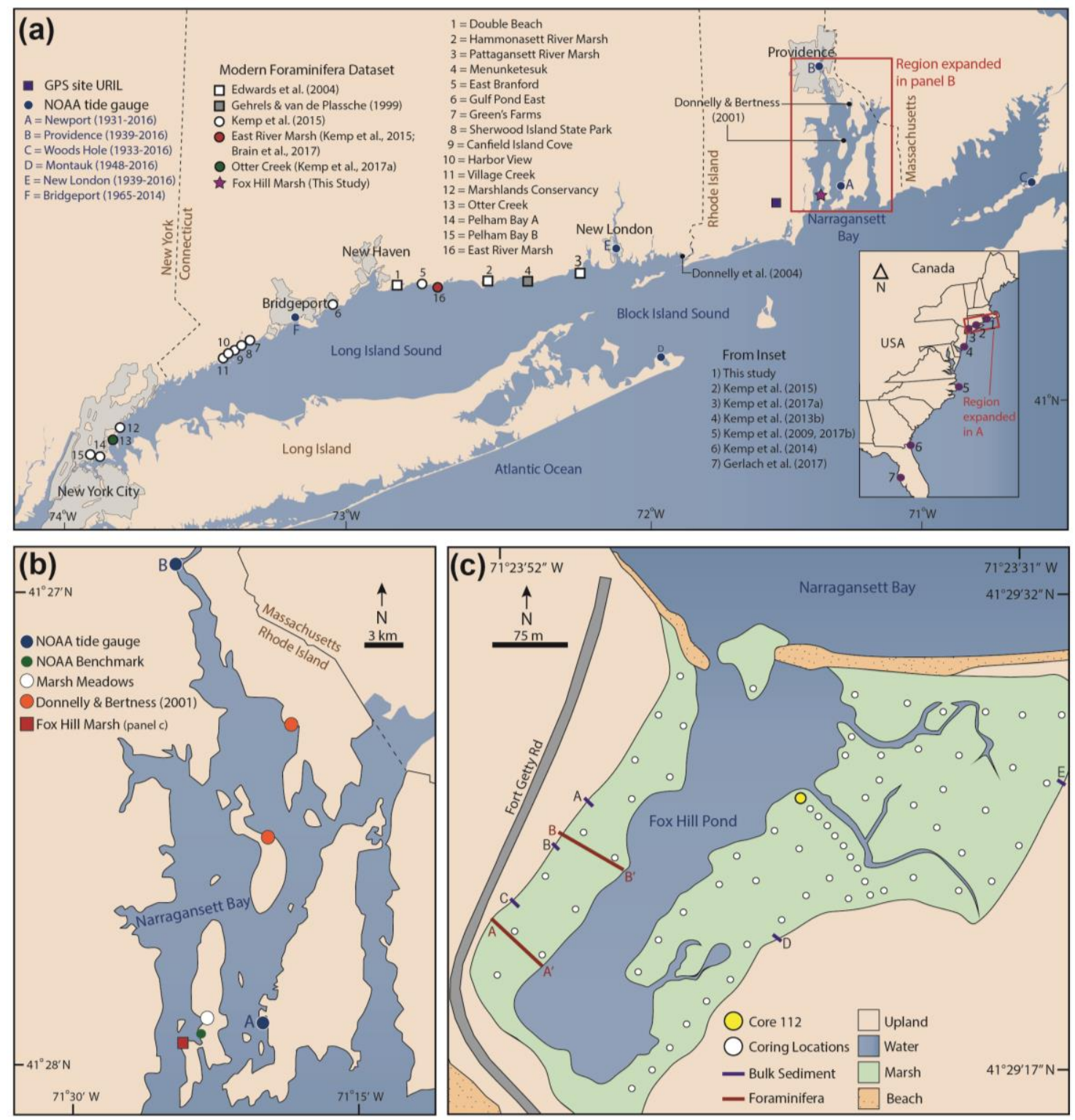

Figure 1. (a) The study area includes our study site, Fox Hill Marsh, within Narragansett Bay (red box) and 16 study sites from previously published work within Long Island Sound (Edwards et al., 2004; Gehrels and van de Plassche, 1999; Kemp et al., 2015) which provide our reconstruction with a regional-scale modern foraminiferal training set. Locations of National Oceanic and Atmospheric Administration (NOAA) tide gauges used to interpret regional relative sea level (RSL) are shown (labeled blue circles; year $\mathrm{CE}$ of establishment is included). GPS site URIL provides a glacial isostatic adjustment rate for the region $(0.9 \mathrm{~mm} / \mathrm{yr}$; blue square; Karegar et al., 2016). The inset shows locations of previous RSL studies on the Atlantic coast. (b) Rhode Island's Narragansett Bay Estuary with the location of Fox Hill Marsh and Marsh Meadows shown on Conanicut Island in the lower bay. Sampled elevations were referenced to tidal datums at 
the Dutch Harbor NOAA benchmark in West Jamestown. Study sites from Donnelly and Bertness (2001) are located on Prudence Island and Rumstick Cove in upper Narragansett Bay. (c) Core and modern transect locations at Fox Hill Marsh. Solid red lines represent modern foraminifera transects (A-A' and B-B'). Dashed red lines correlate to the underlying stratigraphy shown in figure $2\left(\mathrm{X}-\mathrm{X}^{\prime}\right.$ and $\left.\mathrm{Y}-\mathrm{Y}^{\prime}\right)$. Blue lines represent modern bulk sediment transects used for $\delta^{13} \mathrm{C}$ analysis (A-E). 


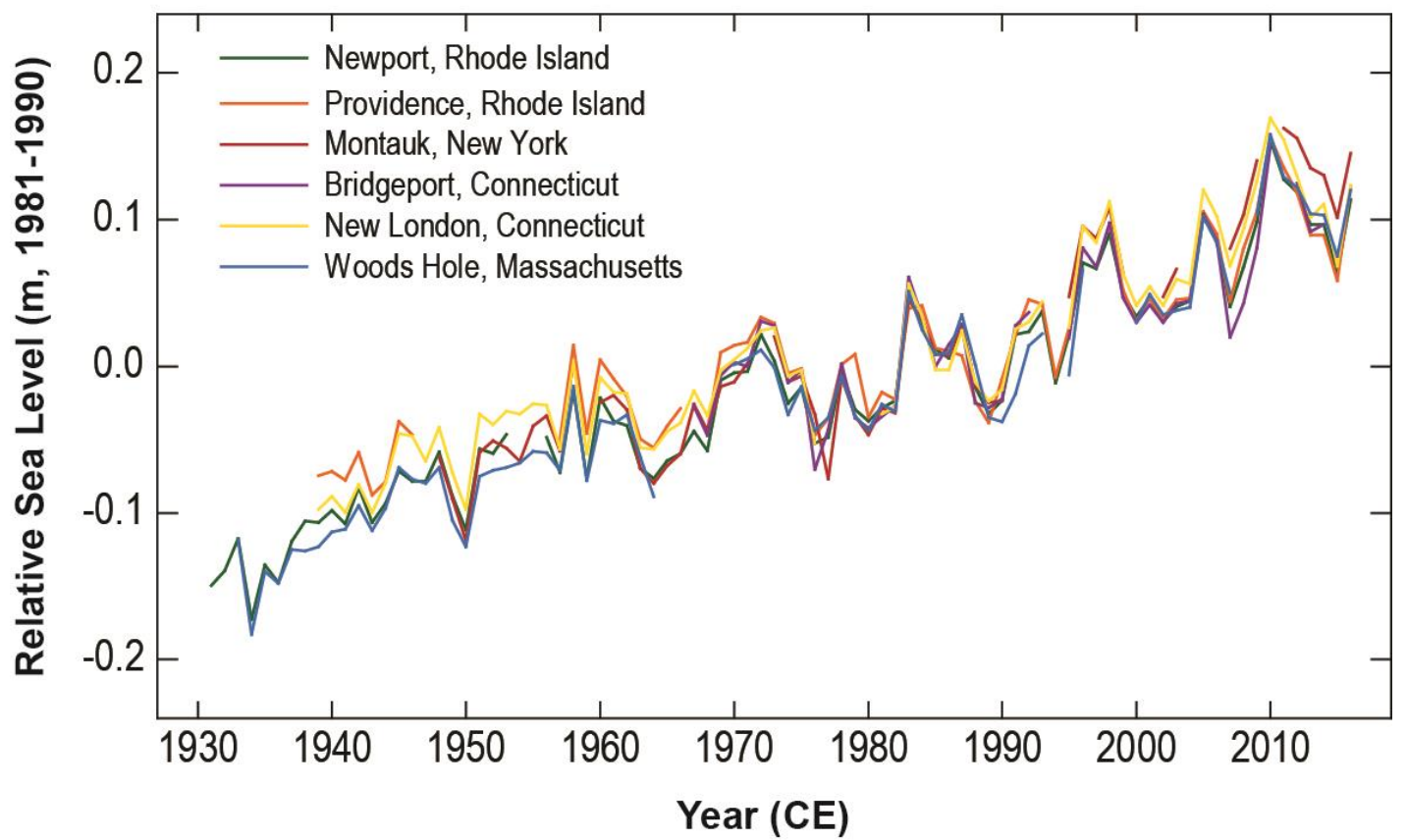

Figure 2. Annual RSL measurements recorded at tide-gauge stations in southern New England (geographic locations are shown in Figure 1a). All tide-gauge data was downloaded from the Permanent Service for Mean Sea Level (PSMSL). Average RSL from 1981-1990 CE is used as the reference period for each tide-gauge series. 


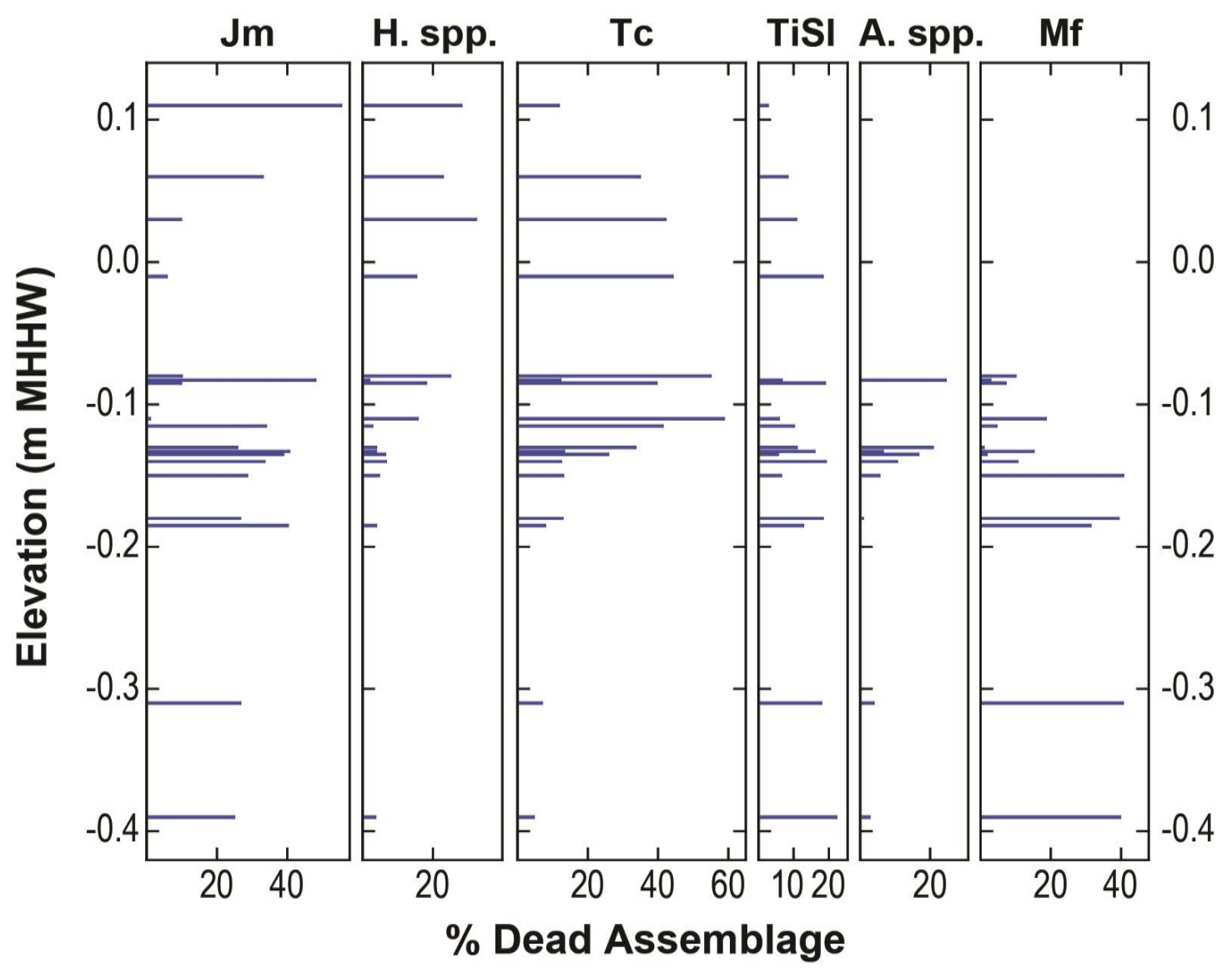

Figure 3. Modern assemblages of foraminifera from 18 samples at Fox Hill Marsh and their corresponding elevation ( $\mathrm{m}$ mean higher high water). Some samples are slightly shifted by $0.002 \mathrm{~m}$ so that they can been seen. 7 of the 15 total taxa identified are presented. Jm: Jadammina macrescens; Tc: Tiphotrocha comprimata; TiSl:

Trochammina inflata and Siphotrocha lobata; Mf: Milliammina fusca; H. spp.:

Haplophragmoides spp.; A. spp.: Ammobaculites spp. 

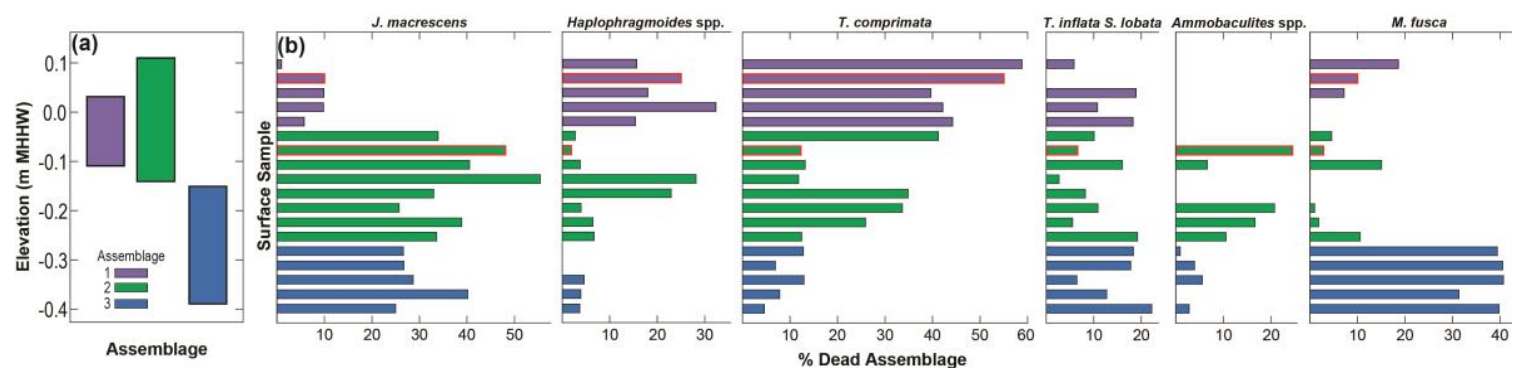

Figure 4. Partitioning around medoids (PAM) cluster analysis recognized three assemblages of modern foraminifera at Fox Hill Marsh represented by colored boxes. (a) Elevational range of assemblages one (purple), two (green), and three (blue) defined by the highest and lowest elevation of samples assigned to each assemblage. Assemblage one ranges from -0.11 to $0.03 \mathrm{~m}$ mean higher high water (MHHW), assemblage two ranges from -0.14 to $0.11 \mathrm{~m}$ MHHW, and assemblage three ranges from -0.93 to -0.15 m MHHW. (b) The most abundant species ( $\geq 83 \%$ in any one sample; 7 of 15 taxa identified) of modern foraminifera at Fox Hill Marsh. Samples lacking an analog in the Kemp et al. (2015) training set are outlined in red. 


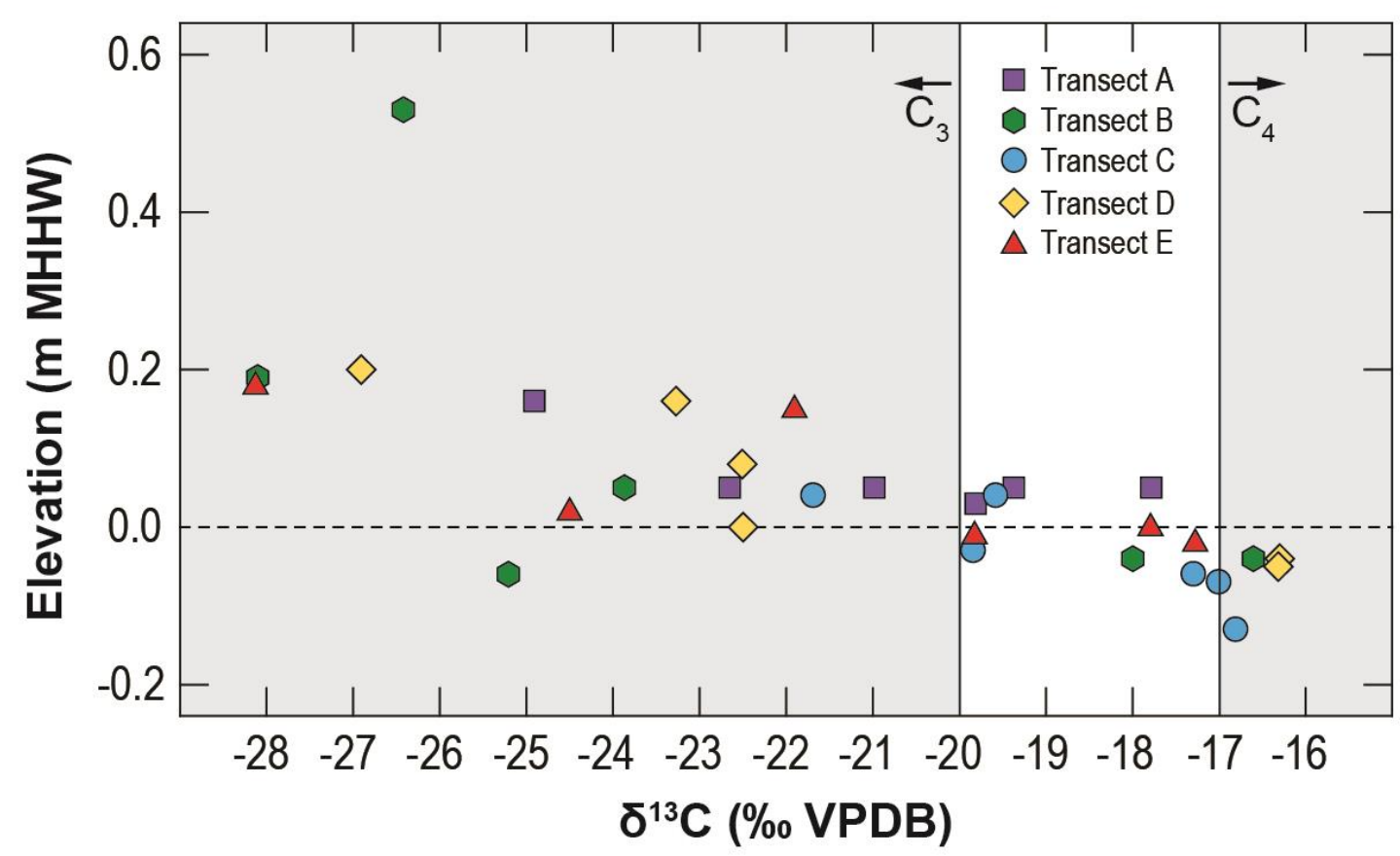

Figure 5. Measured $\delta^{13} \mathrm{C}$ values (relative to the Vienna Pee Dee Belemnite standard; VPDB) bulk sediment from Fox Hill Marsh modern transects (A-E) and the elevation associated with each sample. The right shaded area represents samples from a $\mathrm{C}_{4}$ environment with $\delta^{13} \mathrm{C}$ values less depleted than $-17 \%$. The left shaded area represents samples from a $\mathrm{C}_{3}$ environment with $\delta^{13} \mathrm{C}$ values more depleted than -20\%o. The dashed horizontal line represents the mean higher high water (MHHW) tidal datum. 

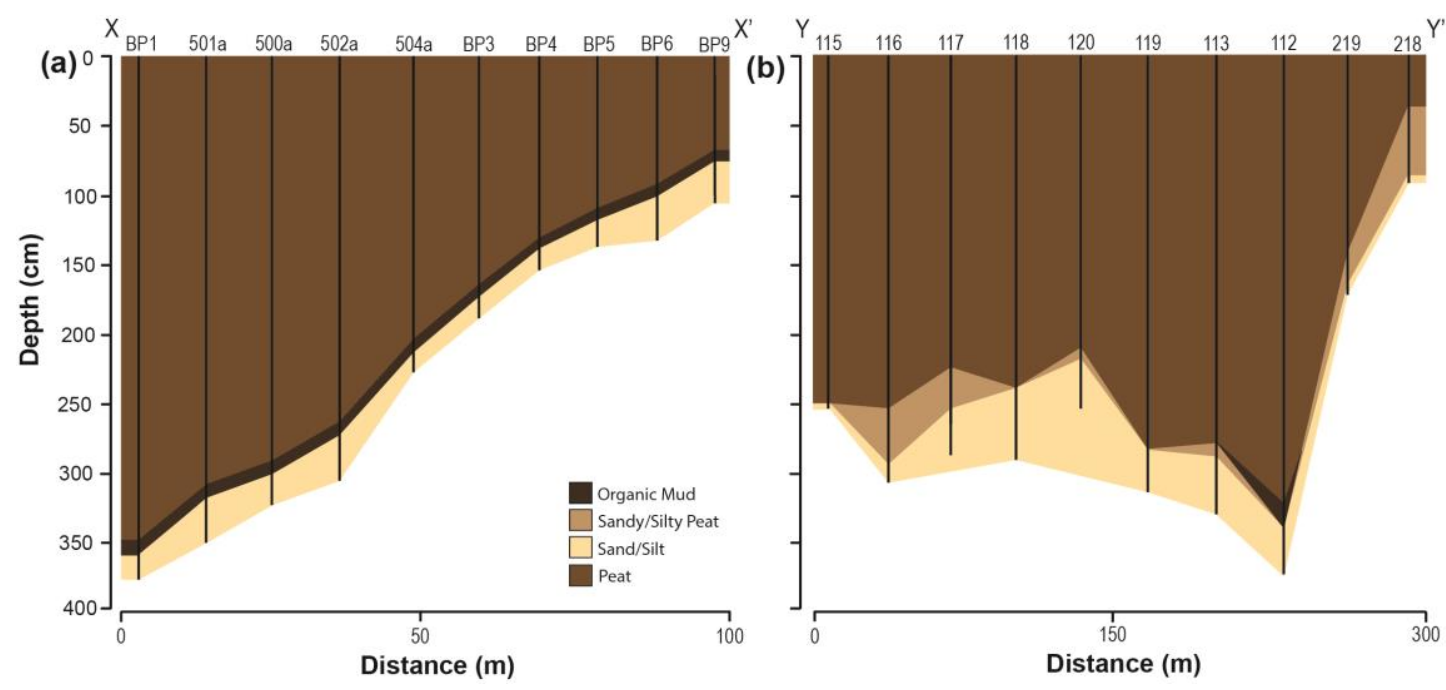

Figure 6. Underlying stratigraphy at Fox Hill Marsh was determined by sampling and describing sediment cores (core number labelled at top). (a) Transect $X-X^{\prime}$ and (b) transect Y-Y' (also containing core FHM-112) follow the coring transects shown in Figure 1c. 


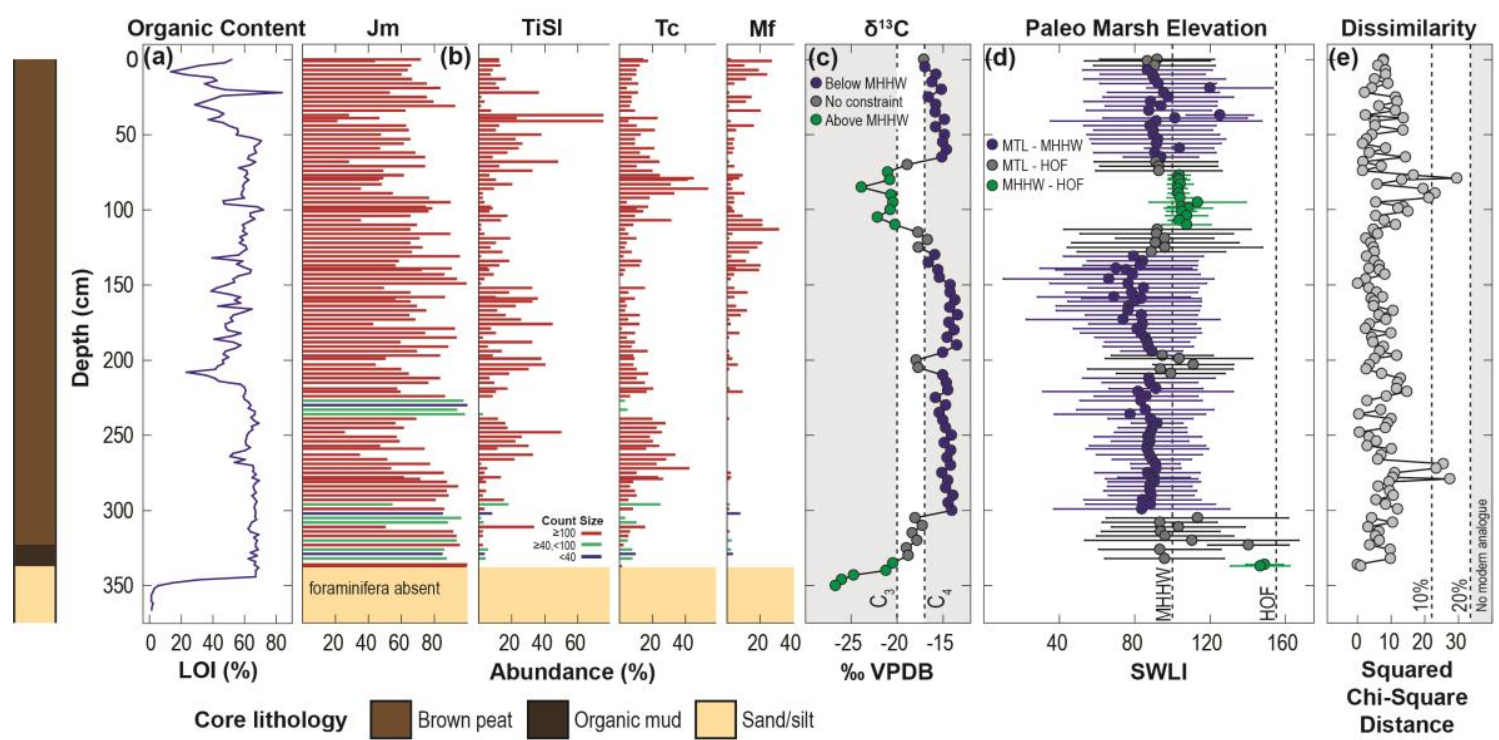

Figure 7. Sea-level indicators and paleomarsh elevation (PME) estimates from core FHM-112. (a) Downcore organic content expressed as percent of loss on ignition (LOI). (b) Abundances of the four most common foraminifera species. The number of individuals counted from each sample are represented by colored bars. Samples that contained less than 40 individuals were excluded from the final reconstruction. (c) $\delta^{13} \mathrm{C}$ values of downcore bulk sediment relative to the Vienna Pee Dee Belemnite (VPDB) standard. Gray shaded regions represent values associated with environments dominated by $\mathrm{C}_{3}$ and $\mathrm{C}_{4}$ plant species. Symbol color represents the prior used to constrain PME estimated by the Bayesian transfer function (B-TF) based off modern $\delta^{13} \mathrm{C}$ values at Fox Hill Marsh. (d) PME (mean with 95\% credible interval) estimates from the B-TF that includes the prior given by bulk sediment $\delta^{13} \mathrm{C}$ measurements. Symbol color represents the prior assigned to each sample. (C) Measured dissimilarity between core samples and their closest modern analog. Dashed vertical lines represent percentiles of dissimilarity measured for all possible pairs of modern samples. Samples do not have a modern analog if they exceed the $20 \%$ threshold (gray shaded region). Jm: Jadammina macrescens; TiSl: combined abundance of Trochammina inflata and Siphotrochammina lobata; Tc:

Tiphotrocha comprimata; Mf: Milliammina fusca; MTL: mean tide level; MHHW: mean higher high water; HOF: highest occurrence of foraminifera; SWLI: standardized water level index. 

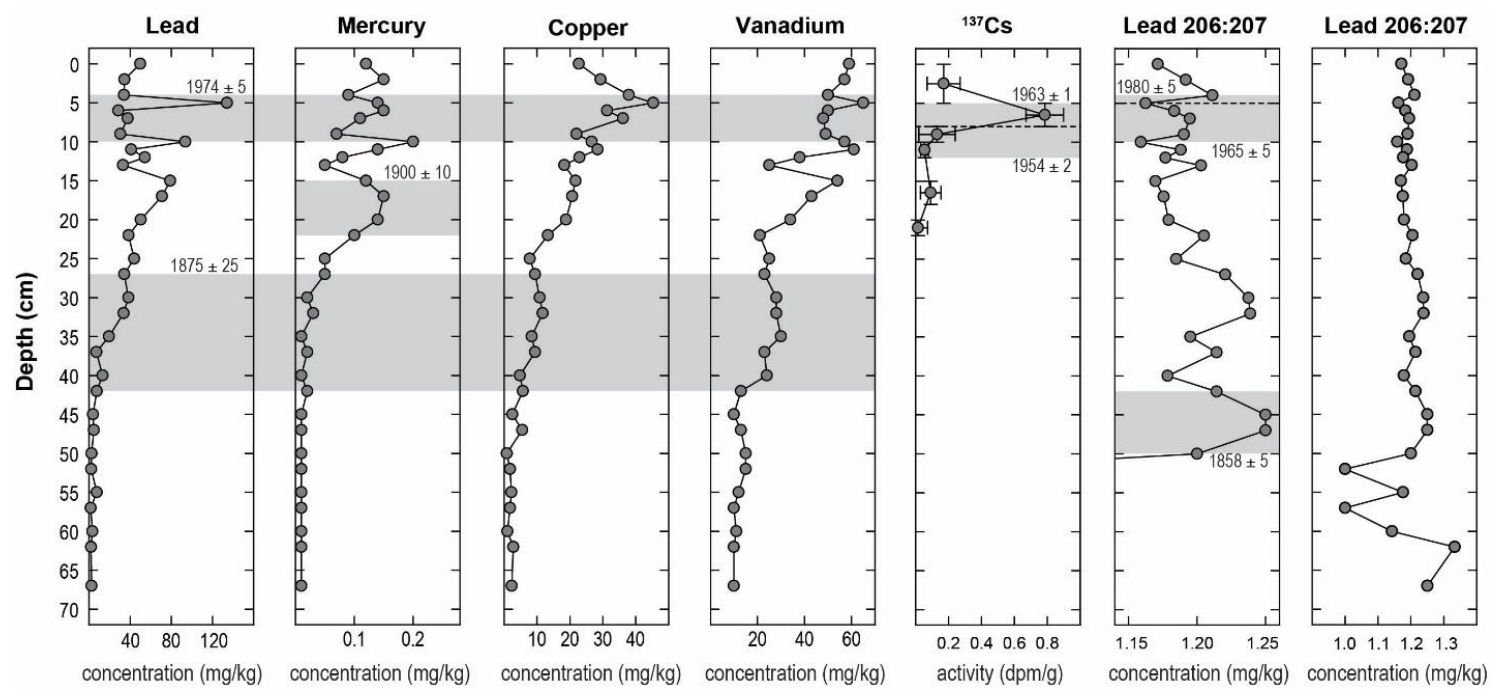

Figure 8. Downcore profiles of ${ }^{137} \mathrm{Cs}$ activity and trace metal and isotopic concentrations used to identify regional pollution markers used in the age-depth model. The lead isotope profile is shown twice with different scales for clarity. Gray shading represents the vertical uncertainty given to each chronohorizon with the associated age (year CE) and age uncertainty of each chronohorizon included next to the shaded area. Chronohorizons are distinguished from one another using horizontal dashed lines where necessary. Analytical uncertainties are smaller than the symbols used. 


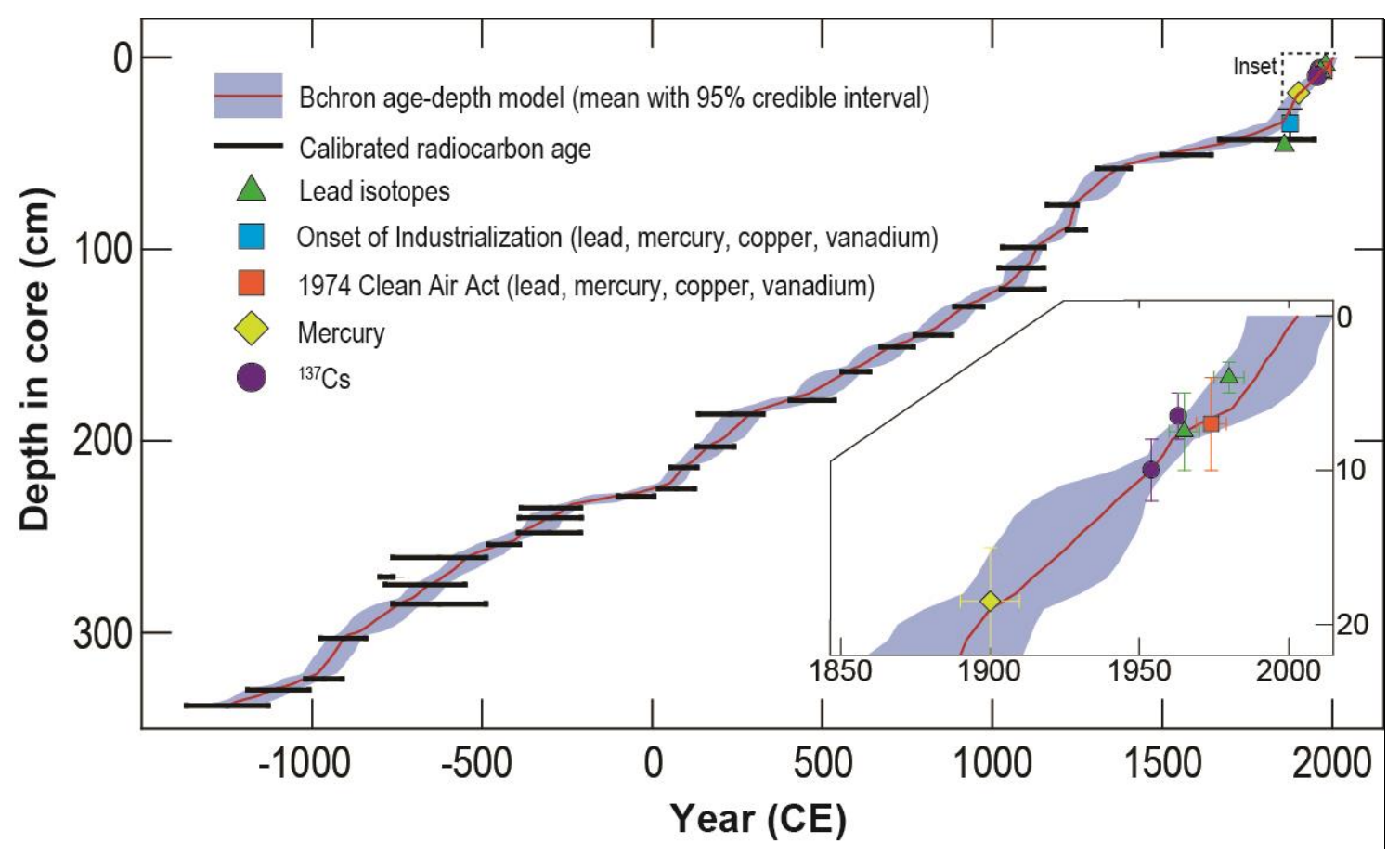

Figure 9. Age-depth model developed for core FHM-112. The 95\% credible interval is represented by the blue envelope. Calibrated radiocarbon ages represent the $2 \sigma$ range between the youngest and oldest possible ages rather than the probability distribution of ages within the range. A detailed chronology for the last $~ 150$ years is shown in the inset. 

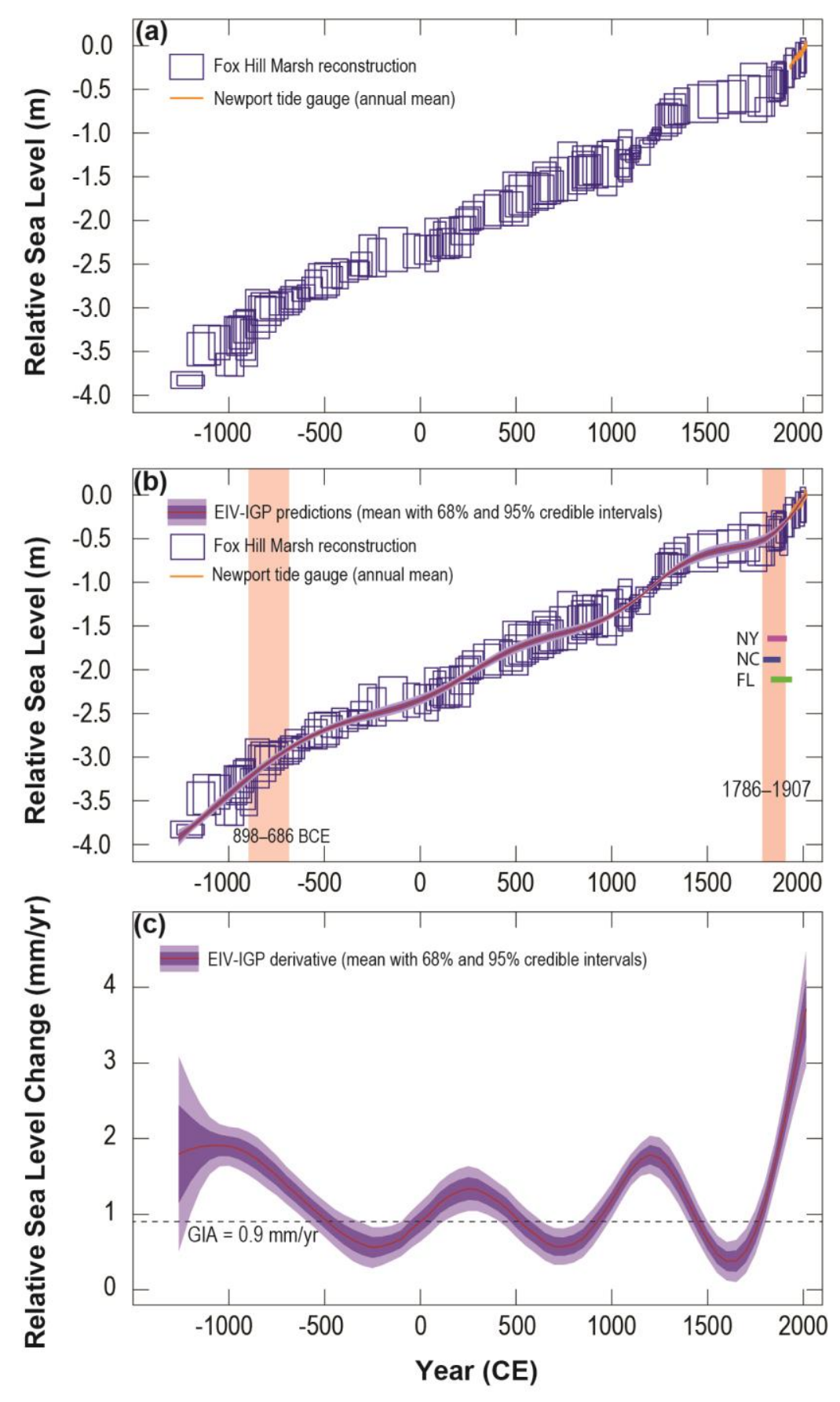

Figure 10. (a) Relative sea level (RSL) reconstructed from Fox Hill Marsh and RSL measurements (annual mean) from the Newport tide gauge. Data points are represented by boxes of vertical and temporal uncertainty $(2 \sigma)$ from the Bayesian transfer function and age-depth model respectively. (b) The Errors-in-Variables Integrated Gaussian Process (EIV-IGP) model and change points (represented by light pink columns) superimposed on the proxy RSL reconstruction. Timings of estimated RSL change points for New York (dark pink; Kemp et al., 2017a), Roanoke, North Carolina (blue; Kemp et al., 2017b), and Florida (green; Gerlach et al., 2017) are also shown and overlap with our 
change point estimate of 1786-1907 CE. (c) Rate of relative sea-level change (including glacial isostatic adjustment (GIA) induced subsidence of $0.9 \mathrm{~mm} / \mathrm{yr}$ ) estimated by the EIV-IGP model. 

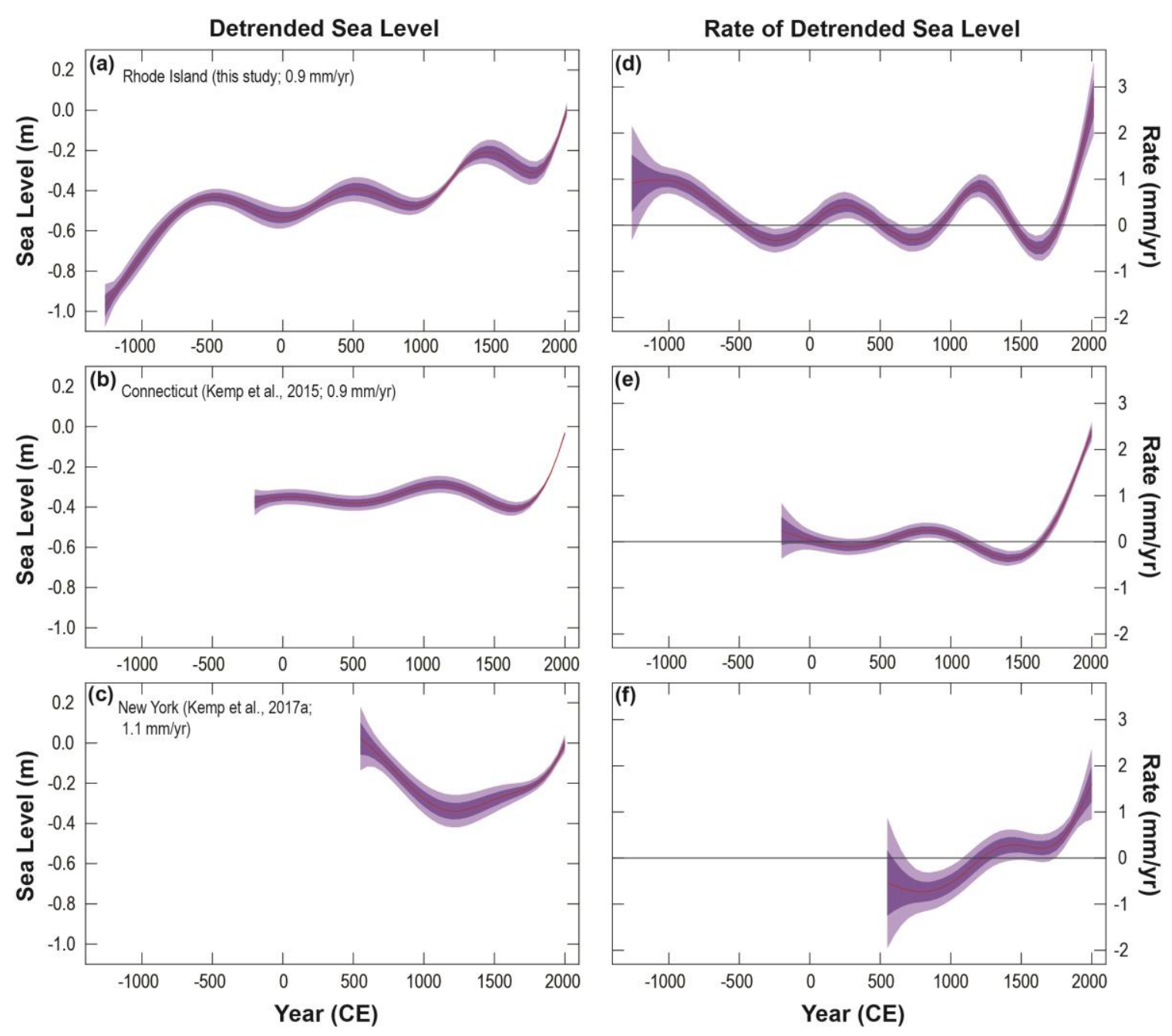

Figure 11. Detrended sea-level (left panels) and rates of detrended sea-level change (mm/yr; right panels) after removing estimates rates of glacial isostatic adjustment (listed in panel titles) in Rhode Island (a, d; this study), Connecticut (b, e; Kemp et al., 2015), and New York (c, f; Kemp et al., 2017a). Trends were estimated using the Errors-invariables Integrated Gaussian Process (EIV-IGP) model to ensure fair comparison between reconstructions and are presented here at identical scales for comparability. 
Table 1. Radiocarbon ages reported by the National Ocean Sciences Accelerator Mass Spectrometry facility from core FHM-112. $\Delta^{13} \mathrm{C}$ values are from an aliquot of $\mathrm{CO}^{2}$ collected during sample combustion.

\begin{tabular}{|c|c|c|c|c|c|c|}
\hline $\begin{array}{l}\text { Depth } \\
\text { (cm) }\end{array}$ & $\begin{array}{l}\text { Sample } \\
\text { ID }\end{array}$ & $\begin{array}{l}\text { Elevation } \\
\text { (m MHHW) }\end{array}$ & ${ }^{14} \mathrm{C}$ Age & $\begin{array}{c}\text { Calibrated Age } \\
\text { (BP) }\end{array}$ & $\begin{array}{c}\delta^{13} \mathrm{C} \\
(\%, \text { VPDB })\end{array}$ & Description \\
\hline 43 & OS-128561 & -0.61 & $155 \pm 15$ & $143 \pm 139$ & -12.22 & D. spicata rhizome \\
\hline 51 & OS-129459 & -0.69 & $315 \pm 15$ & $379 \pm 72$ & -13.14 & D. spicata rhizome \\
\hline 58 & OS-125588 & -0.76 & $590 \pm 15$ & $593 \pm 49$ & -13.12 & D. spicata rhizome \\
\hline 77 & OS-128562 & -0.95 & $845 \pm 20$ & $746 \pm 44$ & -13.50 & D. spicata rhizome \\
\hline 90 & OS-124242 & -1.08 & $780 \pm 20$ & $703 \pm 26$ & -11.06 & D. spicata rhizome \\
\hline 99 & OS-125568 & -1.17 & $940 \pm 15$ & $858 \pm 62$ & -13.63 & D. spicata rhizome \\
\hline 110 & OS-128563 & -1.28 & $970 \pm 15$ & $865 \pm 65$ & -12.13 & D. spicata rhizome \\
\hline 121 & OS-124244 & -1.39 & $950 \pm 15$ & $861 \pm 64$ & -12.24 & D. spicata rhizome \\
\hline 130 & OS-125569 & -1.48 & $1120 \pm 15$ & $1019 \pm 42$ & -12.10 & D. spicata rhizome \\
\hline 145 & OS-125589 & -1.63 & $1200 \pm 15$ & $1124 \pm 54$ & -12.56 & D. spicata rhizome \\
\hline 151 & OS-129379 & -1.69 & $1280 \pm 20$ & $1229 \pm 48$ & -13.02 & D. spicata rhizome \\
\hline 164 & OS-124245 & -1.82 & $1470 \pm 20$ & $1352 \pm 41$ & -12.21 & Unidentified plant stem \\
\hline 179 & OS-125590 & -1.97 & $1600 \pm 20$ & $1479 \pm 65$ & -13.30 & D. spicata rhizome \\
\hline 186 & OS-125591 & -2.04 & $1790 \pm 25$ & $1719 \pm 95$ & -12.92 & D. spicata rhizome \\
\hline 203 & OS-124243 & -2.21 & $1820 \pm 20$ & $1764 \pm 55$ & -13.18 & D. spicata rhizome \\
\hline 214 & OS-125592 & -2.32 & $1910 \pm 20$ & $1858 \pm 39$ & -13.26 & D. spicata rhizome \\
\hline 225 & OS-125668 & -2.43 & $1940 \pm 20$ & $1879 \pm 53$ & -13.43 & D. spicata rhizome \\
\hline 229 & OS-129460 & -2.47 & $2040 \pm 15$ & $1997 \pm 52$ & -13.57 & D. spicata rhizome \\
\hline 235 & OS-131667 & -2.53 & $2250 \pm 15$ & $2249 \pm 87$ & -13.20 & D. spicata rhizome \\
\hline 240 & OS-124248 & -2.58 & $2250 \pm 25$ & $2250 \pm 92$ & -13.75 & D. spicata rhizome \\
\hline 248 & OS-131668 & -2.66 & $2260 \pm 20$ & $2252 \pm 91$ & -13.88 & D. spicata rhizome \\
\hline 254 & OS-125593 & -2.72 & $2360 \pm 20$ & $2387 \pm 47$ & -12.67 ar & $\begin{array}{l}\text { D. spicata rhizome } \\
\text { and unidentified plant stem }\end{array}$ \\
\hline 261 & OS-128564 & -2.79 & $2470 \pm 20$ & $2577 \pm 137$ & -12.79 & D. spicata rhizome \\
\hline 271 & OS-125594 & -2.89 & $2570 \pm 20$ & $2732 \pm 19$ & -13.76 & D. spicata rhizome \\
\hline 275 & OS-128565 & -2.93 & $2520 \pm 15$ & $2618 \pm 117$ & -13.40 & D. spicata rhizome \\
\hline 285 & OS-124249 & -3.03 & $2470 \pm 20$ & $2577 \pm 137$ & -12.64 & D. spicata rhizome \\
\hline 303 & OS-125595 & -3.21 & $2770 \pm 20$ & $2859 \pm 67$ & -12.51 & D. spicata rhizome \\
\hline 324 & OS-124246 & -3.42 & $2820 \pm 20$ & $2916 \pm 54$ & -13.52 & D. spicata rhizome \\
\hline 330 & OS-129461 & -3.48 & $2900 \pm 20$ & $2942 \pm 17$ & -13.08 & D. spicata rhizome \\
\hline 338 & OS-124247 & -3.56 & $3000 \pm 20$ & $3199 \pm 120$ & -12.53 & D. spicata rhizome \\
\hline
\end{tabular}


Table 2. Downcore concentrations of ${ }^{137} \mathrm{Cs}$ activity and trace metal concentrations in core FHM-112 used to determine age markers during the last 200 years. Values used to interpret pollution markers are highlighted for clarification.

\begin{tabular}{|c|c|c|c|c|c|c|c|c|c|}
\hline Sample & $\begin{array}{l}\text { Depth } \\
\text { (cm) }\end{array}$ & $\begin{array}{c}\text { Copper } \\
\text { (ppm) }\end{array}$ & $\begin{array}{c}\text { Mercury } \\
\text { (ppm) }\end{array}$ & $\begin{array}{c}\text { Vanadium } \\
\text { (ppm) }\end{array}$ & $\begin{array}{l}\text { Lead } \\
\text { (ppm) }\end{array}$ & $\begin{array}{l}\text { Lead } 206 \\
\quad(p p m)\end{array}$ & $\begin{array}{l}\text { Lead } 207 \\
\quad(p p m)\end{array}$ & $\begin{array}{l}\text { Lead } \\
\text { 206:207 }\end{array}$ & $\begin{array}{c}{ }^{137} \text { Cs activity } \\
\text { (dpm/g) }\end{array}$ \\
\hline FHM.15.112.E 0-1 cm & 0 & 22.7 & 0.12 & 59 & 49.7 & 12.3 & 10.5 & 1.17 & - \\
\hline FHM. $15.112 . \mathrm{F} 2-3 \mathrm{~cm}$ & 2 & 29.3 & 0.15 & 57 & 34.4 & 8.7 & 7.3 & 1.19 & - \\
\hline FHM.15.112.G $0-5 \mathrm{~cm}$ & 2.5 & - & - & - & - & - & - & - & $0.17 \pm 0.1$ \\
\hline FHM.15.112.E 4-5 cm & 4 & 37.9 & 0.09 & 50 & 33.9 & 8.6 & 7.1 & 1.21 & - \\
\hline FHM. $15.112 . \mathrm{F} 5-6 \mathrm{~cm}$ & 5 & 45.3 & 0.14 & 65 & 134 & 32.2 & 27.7 & 1.16 & - \\
\hline FHM.15.112.E 6-7 cm & 6 & 31.3 & 0.15 & 50 & 28.4 & 7.1 & 6 & 1.18 & - \\
\hline FHM.15.112.G 5-8 cm & 6.5 & - & - & - & - & - & - & - & $0.79 \pm 0.11$ \\
\hline FHM.15.112.F 7-8 cm & 7 & 36.1 & 0.11 & 48 & 37.6 & 9.2 & 7.7 & 1.19 & - \\
\hline FHM.15.112.G 8-10 cm & 9 & - & - & - & - & - & - & - & $0.13 \pm 0.11$ \\
\hline FHM.15.112.E 9-10 cm & 9 & 22 & 0.07 & 49 & 30.3 & 7.5 & 6.3 & 1.19 & - \\
\hline FHM.15.112.F $10-11 \mathrm{~cm}$ & 10 & 26.6 & 0.2 & 57 & 93.6 & 22.6 & 19.5 & 1.16 & - \\
\hline FHM.15.112.G $10-12 \mathrm{~cm}$ & 11 & - & - & - & - & - & - & - & $0.05 \pm 0.02$ \\
\hline FHM.15.112.E $11-12 \mathrm{~cm}$ & 11 & 28.4 & 0.14 & 61 & 40.9 & 10.1 & 8.5 & 1.19 & - \\
\hline FHM. $15.112 . F 12-13 \mathrm{~cm}$ & 12 & 22.9 & 0.08 & 38 & 54.1 & 13.3 & 11.3 & 1.18 & - \\
\hline FHM.15.112.E $13-14 \mathrm{~cm}$ & 13 & 18.3 & 0.05 & 25 & 32.9 & 8.3 & 6.9 & 1.20 & - \\
\hline FHM. $15.112 . F$ 15-16 cm & 15 & 21.7 & 0.12 & 54 & 78.8 & 19.3 & 16.5 & 1.17 & - \\
\hline FHM.15.112.G $15-18 \mathrm{~cm}$ & 16.5 & - & - & - & - & - & - & - & $0.09 \pm 0.06$ \\
\hline FHM. $15.112 . \mathrm{F} 17-18 \mathrm{~cm}$ & 17 & 20.7 & 0.15 & 43 & 70.8 & 17.4 & 14.8 & 1.18 & - \\
\hline FHM.15.112.F 20-21 cm & 20 & 18.8 & 0.14 & 34 & 50.2 & 12.5 & 10.6 & 1.18 & - \\
\hline FHM.15.112.G 20-22 cm & 21 & - & - & - & - & - & - & - & $0.01 \pm 0.06$ \\
\hline FHM. $15.112 . F 22-23 \mathrm{~cm}$ & 22 & 13.3 & 0.1 & 21 & 38.3 & 9.4 & 7.8 & 1.21 & - \\
\hline FHM. $15.112 . \mathrm{F} 25-26 \mathrm{~cm}$ & 25 & 7.8 & 0.05 & 25 & 43.8 & 10.9 & 9.2 & 1.18 & - \\
\hline FHM. $15.112 . F 27-28 \mathrm{~cm}$ & 27 & 9.4 & 0.05 & 23 & 34.1 & 8.3 & 6.8 & 1.22 & - \\
\hline FHM.15.112.F $30-31 \mathrm{~cm}$ & 30 & 10.8 & 0.02 & 28 & 38.1 & 9.9 & 8 & 1.24 & - \\
\hline FHM. $15.112 . F 32-33 \mathrm{~cm}$ & 32 & 11.7 & 0.03 & 28 & 33.6 & 8.3 & 6.7 & 1.24 & - \\
\hline FHM. $15.112 . F 35-36 \mathrm{~cm}$ & 35 & 8.4 & 0.01 & 30 & 19.3 & 4.9 & 4.1 & 1.20 & - \\
\hline FHM. $15.112 . F 37-38 \mathrm{~cm}$ & 37 & 9.4 & 0.02 & 23 & 7.2 & 1.7 & 1.4 & 1.21 & - \\
\hline FHM. $15.112 . F \quad 40-41 \mathrm{~cm}$ & 40 & 4.8 & 0.01 & 24 & 13.1 & 3.3 & 2.8 & 1.18 & - \\
\hline FHM.15.112.F $42-43 \mathrm{~cm}$ & 42 & 5.7 & 0.02 & 13 & 7.4 & 1.7 & 1.4 & 1.21 & - \\
\hline FHM.15.112.F $45-46 \mathrm{~cm}$ & 45 & 2.5 & $<0.01$ & 10 & 3.8 & 1 & 0.8 & 1.25 & - \\
\hline FHM. $15.112 . F \quad 47-48 \mathrm{~cm}$ & 47 & 5.5 & 0.01 & 13 & 4.5 & 1 & 0.8 & 1.25 & - \\
\hline FHM. $15.112 . F 50-51 \mathrm{~cm}$ & 50 & 0.8 & $<0.01$ & 15 & 2.3 & 0.6 & 0.5 & 1.20 & - \\
\hline FHM. $15.112 . F 52-53 \mathrm{~cm}$ & 52 & 1.8 & $<0.01$ & 15 & 2 & 0.4 & 0.4 & 1.00 & - \\
\hline FHM. $15.112 . F 55-56 \mathrm{~cm}$ & 55 & 2.2 & $<0.01$ & 12 & 7.5 & 2 & 1.7 & 1.18 & - \\
\hline FHM. $15.112 . F 57-58 \mathrm{~cm}$ & 57 & 1.8 & $<0.01$ & 10 & 1.5 & 0.3 & 0.3 & 1.00 & - \\
\hline FHM. $15.112 . F$ 60-61 cm & 60 & 1 & $<0.01$ & 11 & 3.2 & 0.8 & 0.7 & 1.14 & - \\
\hline FHM.15.112.F $62-63 \mathrm{~cm}$ & 62 & 2.8 & 0.01 & 10 & 1.9 & 0.4 & 0.3 & 1.33 & - \\
\hline FHM. $15.112 . F \quad 67-68 \mathrm{~cm}$ & 67 & 2.3 & $<0.01$ & 10 & 2.4 & 0.5 & 0.4 & 1.25 & - \\
\hline
\end{tabular}


Table 3. Paleomarsh elevation (PME) estimates in standardized water level index (SWLI) and mean higher high water (MHHW) with a $2 \sigma$ uncertainty given by the Bayesian transfer function. Priors assigned to each sample are listed.

\begin{tabular}{|c|c|c|c|c|c|c|c|c|c|c|c|c|c|}
\hline $\begin{array}{l}\text { Depth } \\
(\mathrm{cm})\end{array}$ & $\begin{array}{l}\text { Elevation } \\
\text { (m MHHW) }\end{array}$ & $\begin{array}{l}\text { PME } \\
\text { (SWLI) }\end{array}$ & $\begin{array}{l}\text { PME error } \\
\text { (SWLI) }\end{array}$ & $\begin{array}{c}\text { PME } \\
\text { (m MHHW) }\end{array}$ & $\begin{array}{l}\text { PME error } \\
(\mathrm{m})\end{array}$ & \begin{tabular}{c|} 
Assigned \\
Prior (SWLI)
\end{tabular} & $\begin{array}{l}\text { Depth } \\
\text { (cm) }\end{array}$ & $\begin{array}{l}\text { Elevation } \\
\text { (m MHHW) }\end{array}$ & $\begin{array}{l}\text { PME } \\
\text { (SWLI) }\end{array}$ & $\begin{array}{l}\text { PME error } \\
\text { (SWLI) }\end{array}$ & $\begin{array}{c}\text { PME } \\
\text { (m MHHW) }\end{array}$ & $\begin{array}{l}\text { PME error } \\
(\mathrm{m})\end{array}$ & $\begin{array}{l}\text { Assigned } \\
\text { Prior (SWLI) }\end{array}$ \\
\hline 0 & -0.18 & 92 & 30 & -0.05 & 0.18 & $0-155$ & 161 & -1.79 & 80 & 35 & -0.12 & 0.21 & $0-100$ \\
\hline 1 & -0.19 & 87 & 33 & -0.08 & 0.20 & $0-155$ & 164 & -1.82 & 77 & 38 & -0.14 & 0.23 & $0-100$ \\
\hline 4 & -0.22 & 90 & 32 & -0.06 & 0.19 & $0-155$ & 167 & -1.85 & 76 & 38 & -0.14 & 0.23 & $0-100$ \\
\hline 7 & -0.25 & 87 & 34 & -0.08 & 0.20 & $0-100$ & 170 & -1.88 & 83 & 30 & -0.10 & 0.18 & $0-100$ \\
\hline 10 & -0.28 & 89 & 28 & -0.06 & 0.17 & $0-100$ & 173 & -1.91 & 74 & 51 & -0.16 & 0.31 & $0-100$ \\
\hline 13 & -0.31 & 90 & 38 & -0.06 & 0.22 & $0-100$ & 176 & -1.94 & 84 & 28 & -0.10 & 0.17 & $0-100$ \\
\hline 16 & -0.34 & 92 & 31 & -0.05 & 0.18 & $0-100$ & 179 & -1.97 & 81 & 34 & -0.11 & 0.20 & $0-100$ \\
\hline 19 & -0.37 & 120 & 33 & 0.12 & 0.20 & $0-100$ & 182 & -2.00 & 83 & 32 & -0.10 & 0.19 & $0-100$ \\
\hline 22 & -0.40 & 95 & 30 & -0.03 & 0.18 & $0-100$ & 185 & -2.03 & 86 & 27 & -0.09 & 0.16 & $0-100$ \\
\hline 25 & -0.43 & 98 & 35 & -0.01 & 0.21 & $0-100$ & 188 & -2.06 & 87 & 22 & -0.08 & 0.13 & $0-100$ \\
\hline 28 & -0.46 & 88 & 35 & -0.07 & 0.21 & $0-100$ & 191 & -2.09 & 87 & 24 & -0.08 & 0.14 & $0-100$ \\
\hline 31 & -0.49 & 94 & 30 & -0.04 & 0.18 & $0-100$ & 194 & -2.12 & 89 & 16 & -0.07 & 0.10 & $0-100$ \\
\hline 34 & -0.52 & 87 & 33 & -0.07 & 0.20 & $0-100$ & 197 & -2.15 & 95 & 27 & -0.03 & 0.16 & $0-155$ \\
\hline 37 & -0.55 & 125 & 18 & 0.15 & 0.11 & $0-100$ & 199 & -2.17 & 103 & 39 & 0.02 & 0.23 & $0-155$ \\
\hline 39 & -0.57 & 101 & 38 & 0.01 & 0.23 & $0-100$ & 203 & -2.21 & 111 & 21 & 0.07 & 0.13 & $0-155$ \\
\hline 41 & -0.59 & 91 & 56 & -0.05 & 0.33 & $0-100$ & 206 & -2.24 & 94 & 39 & -0.04 & 0.23 & $0-155$ \\
\hline 44 & -0.62 & 88 & 35 & -0.07 & 0.21 & $0-100$ & 209 & -2.27 & 99 & 29 & -0.01 & 0.17 & $0-155$ \\
\hline 47 & -0.65 & 90 & 31 & -0.06 & 0.19 & $0-100$ & 212 & -2.30 & 87 & 35 & -0.07 & 0.21 & $0-100$ \\
\hline 50 & -0.68 & 90 & 35 & -0.06 & 0.21 & $0-100$ & 215 & -2.33 & 88 & 25 & -0.07 & 0.15 & $0-100$ \\
\hline 53 & -0.71 & 92 & 36 & -0.05 & 0.21 & $0-100$ & 219 & -2.37 & 91 & 25 & -0.05 & 0.15 & $0-100$ \\
\hline 56 & -0.74 & 92 & 34 & -0.05 & 0.20 & $0-100$ & 221 & -2.39 & 82 & 50 & -0.11 & 0.30 & $0-100$ \\
\hline 59 & -0.77 & 104 & 18 & 0.02 & 0.11 & $0-100$ & 224 & -2.42 & 86 & 27 & -0.08 & 0.16 & $0-100$ \\
\hline 62 & -0.80 & 91 & 32 & -0.06 & 0.19 & $0-100$ & 227 & -2.45 & 83 & 32 & -0.10 & 0.19 & $0-100$ \\
\hline 65 & -0.83 & 94 & 20 & -0.04 & 0.12 & $0-100$ & 233 & -2.51 & 86 & 36 & -0.09 & 0.22 & $0-100$ \\
\hline 68 & -0.86 & 91 & 33 & -0.05 & 0.20 & $0-155$ & 236 & -2.54 & 77 & 40 & -0.13 & 0.24 & $0-100$ \\
\hline 71 & -0.89 & 93 & 31 & -0.04 & 0.19 & $0-155$ & 239 & -2.57 & 88 & 23 & -0.07 & 0.13 & $0-100$ \\
\hline 74 & -0.92 & 93 & 33 & -0.04 & 0.20 & $0-155$ & 242 & -2.60 & 92 & 14 & -0.05 & 0.08 & $0-100$ \\
\hline 77 & -0.95 & 104 & 6 & 0.02 & 0.03 & $100-155$ & 245 & -2.63 & 89 & 18 & -0.06 & 0.11 & $0-100$ \\
\hline 79 & -0.97 & 103 & 5 & 0.02 & 0.03 & $100-155$ & 248 & -2.66 & 88 & 19 & -0.07 & 0.11 & $0-100$ \\
\hline 80 & -0.98 & 103 & 6 & 0.02 & 0.03 & $100-155$ & 251 & -2.69 & 87 & 28 & -0.08 & 0.17 & $0-100$ \\
\hline 83 & -1.01 & 104 & 7 & 0.02 & 0.04 & $100-155$ & 254 & -2.72 & 88 & 20 & -0.07 & 0.12 & $0-100$ \\
\hline 86 & -1.04 & 103 & 5 & 0.02 & 0.03 & $100-155$ & 257 & -2.75 & 87 & 31 & -0.08 & 0.18 & $0-100$ \\
\hline 89 & -1.07 & 103 & 6 & 0.02 & 0.03 & $100-155$ & 259 & -2.77 & 87 & 32 & -0.08 & 0.19 & $0-100$ \\
\hline 92 & -1.10 & 104 & 7 & 0.02 & 0.04 & $100-155$ & 263 & -2.81 & 88 & 28 & -0.07 & 0.17 & $0-100$ \\
\hline 95 & -1.13 & 113 & 26 & 0.08 & 0.15 & $100-155$ & 266 & -2.84 & 89 & 21 & -0.07 & 0.12 & $0-100$ \\
\hline 98 & -1.16 & 105 & 7 & 0.03 & 0.04 & $100-155$ & 269 & -2.87 & 91 & 13 & -0.05 & 0.08 & $0-100$ \\
\hline 99 & -1.17 & 108 & 13 & 0.05 & 0.08 & $100-155$ & 272 & -2.90 & 91 & 13 & -0.05 & 0.08 & $0-100$ \\
\hline 101 & -1.19 & 105 & 8 & 0.03 & 0.05 & $100-155$ & 275 & -2.93 & 87 & 28 & -0.08 & 0.17 & $0-100$ \\
\hline 104 & -1.22 & 107 & 11 & 0.04 & 0.07 & $100-155$ & 278 & -2.96 & 90 & 19 & -0.06 & 0.11 & $0-100$ \\
\hline 107 & -1.25 & 104 & 6 & 0.02 & 0.03 & $100-155$ & 279 & -2.97 & 89 & 24 & -0.07 & 0.15 & $0-100$ \\
\hline 110 & -1.28 & 107 & 13 & 0.04 & 0.08 & $100-155$ & 281 & -2.99 & 90 & 24 & -0.06 & 0.15 & $0-100$ \\
\hline 113 & -1.31 & 92 & 50 & -0.05 & 0.30 & $0-155$ & 284 & -3.02 & 88 & 22 & -0.07 & 0.13 & $0-100$ \\
\hline 116 & -1.34 & 92 & 41 & -0.05 & 0.24 & $0-155$ & 287 & -3.05 & 88 & 25 & -0.07 & 0.15 & $0-100$ \\
\hline 119 & -1.37 & 96 & 26 & -0.02 & 0.16 & $0-155$ & 290 & -3.08 & 89 & 23 & -0.07 & 0.14 & $0-100$ \\
\hline 122 & -1.40 & 91 & 44 & -0.05 & 0.26 & $0-155$ & 293 & -3.11 & 84 & 31 & -0.10 & 0.19 & $0-100$ \\
\hline 125 & -1.43 & 96 & 52 & -0.02 & 0.31 & $0-155$ & 296 & -3.14 & 88 & 34 & -0.07 & 0.21 & $0-100$ \\
\hline 128 & -1.46 & 89 & 39 & -0.07 & 0.23 & $0-155$ & 299 & -3.17 & 84 & 47 & -0.10 & 0.28 & $0-100$ \\
\hline 131 & -1.49 & 79 & 37 & -0.12 & 0.22 & $0-100$ & 305 & -3.23 & 113 & 48 & 0.08 & 0.29 & $0-155$ \\
\hline 134 & -1.52 & 84 & 29 & -0.09 & 0.18 & $0-100$ & 308 & -3.26 & 93 & 30 & -0.04 & 0.18 & $0-155$ \\
\hline 137 & -1.55 & 83 & 30 & -0.10 & 0.18 & $0-100$ & 311 & -3.29 & 103 & 35 & 0.02 & 0.21 & $0-155$ \\
\hline 139 & -1.57 & 70 & 40 & -0.18 & 0.24 & $0-100$ & 314 & -3.32 & 94 & 31 & -0.04 & 0.19 & $0-155$ \\
\hline 140 & -1.58 & 76 & 37 & -0.15 & 0.22 & $0-100$ & 317 & -3.35 & 96 & 36 & -0.02 & 0.22 & $0-155$ \\
\hline 143 & -1.61 & 79 & 36 & -0.13 & 0.21 & $0-100$ & 320 & -3.38 & 110 & 57 & 0.06 & 0.34 & $0-155$ \\
\hline 146 & -1.64 & 66 & 56 & -0.20 & 0.33 & $0-100$ & 323 & -3.41 & 140 & 21 & 0.24 & 0.13 & $0-155$ \\
\hline 149 & -1.67 & 76 & 41 & -0.14 & 0.25 & $0-100$ & 326 & -3.44 & 93 & 32 & -0.04 & 0.19 & $0-155$ \\
\hline 152 & -1.70 & 85 & 29 & -0.09 & 0.18 & $0-100$ & 332 & -3.50 & 96 & 32 & -0.03 & 0.19 & $0-155$ \\
\hline 155 & -1.73 & 78 & 35 & -0.13 & 0.21 & $0-100$ & 336 & -3.54 & 149 & 10 & 0.29 & 0.06 & $100-155$ \\
\hline 158 & -1.76 & 69 & 40 & -0.19 & 0.24 & $0-100$ & 337 & -3.55 & 146 & 16 & 0.28 & 0.09 & $100-155$ \\
\hline 159 & -1.77 & 84 & 32 & -0.10 & 0.19 & $0-100$ & & & & & & & \\
\hline
\end{tabular}




\section{BIBLIOGRAPHY}

Barlow NLM, Shennan I, Long AJ et al (2013) Salt marshes as late Holocene tide gauges. Global and Planetary Change 106: 90-110.

Barnhardt WA, Gehrels WR, Belknap DF et al. (1995) Late Quaternary relative sea-level change in the western Gulf of Maine: Evidence for a migrating glacial forebulge. Geology 23(4): 317-320.

Bertness M (1992) The Ecology of a New England Salt Marsh. American Scientists 80(3): 260-268.

Bollhöfer A and Rosman KJR (2001) Isotopic source signatures for atmospheric lead: The Northern Hemisphere. Geochimica et Cosmochimica Acta 65: 1727-1740.

Brain MJ, Kemp AC, Horton BP et al (2015) Quantifying the contribution of sediment compaction to late Holocene salt-marsh sea-level reconstructions, North Carolina, USA. Quaternary Research 83: 41-51.

Brain MJ, Kemp AC, Hawkes AD et al. (2017) Exploring mechanisms of compaction in salt-marsh sediments using Common Era relative sea-level reconstructions. Quaternary Science Reviews 167: 96-111.

Bricker-Urso S and Nixon SW (1984) Final Report to the Narragansett Bay Estuarine Sanctuary Scientific Committee: The Impact of Human Activities on the Prudence Island Estuarine Sanctuary as Shown by Historical Changes in Heavy Metal Inputs and Vegetation. Graduate School of Oceanography, University of Rhode Island.

Bricker-Urso S, Nixon SW, Cochran JK et al (1989) Accretion Rates and Sediment Accumulation in Rhode Island Salt Marshes. Estuaries 12(4): 300-317.

Brodie CR, Leng MJ, Casford JSL et al (2011) Evidence for bias in C and N concentrations and $\delta^{13} \mathrm{C}$ composition of terrestrial and aquatic organic materials due to pre-analysis acid preparation methods. Chemical Geology 282: 67-83.

Cahill N, Kemp AC, Horton BP et al (2015). Modeling sea-level change using errors-invariables integrated Gaussian processes. The Annals of Applied Statistics 9(2): 547-571.

Cahill N, Kemp AC, Parnell AC et al. (2016) A Bayesian hierarchical model for reconstructing relative sea level: From raw data to rates. Climate of the Past 12: $525-542$.

Carter M and Moghissi A (1977) Three decades of nuclear testing. Health Physics 33:5571. 
Center for Operational Oceanographic Products and Services [CO-OPS] (2013a) Datums for 8453742, West Jamestown RI.

https://tidesandcurrents.noaa.gov/datums.html?units=1\&epoch=0\&id=8453742\& name $=$ WEST+JAMESTOWN\&state $=$ RI.

Center for Operational Oceanographic Products and Services [CO-OPS] (2013b) Newport, RI - Station ID: 8452660. Retrieved from https://tidesandcurrents.noaa.gov/stationhome.html?id=8452660.

Chmura GL and Aharon P (1995) Stable Carbon Isotope Signatures of Sedimentary Carbon in Coastal Wetlands as Indicators of Salinity Regime. Journal of Coastal Research 11: 124-135.

Church JA, White NJ, Aarup T et al. (2008) Understanding global sea levels: past, present and future. Sustainability Science 3: 9-22.

Clark JA, Farrell WE and Peltier WR (1978) Global Changes in Postglacial Sea Level: a Numerical Calculation. Quaternary Research 9: 265-287.

Corbett DR, Walsh JP and Marciniak K (2009) Temporal and Spatial Variability in the Trace Metals of Two Adjacent Tributaries of the Neuse River Estuary, NC. Marine Pollution Bulletin 58(11): 1739-1747.

Corbett DR and Walsh JP (2015) ${ }^{210} \mathrm{~Pb}$ and ${ }^{137}$ Cesium: establishing a chronology for the last century. In: Shennan I, Long AJ and Horton BP (eds) Handbook of Sea-Level Research. Chichester, West Sussex: John Wiley \& Sons, Ltd., pp.361-372.

Crain CM, Albertson LK and Bertness MD (2008) Secondary Succession Dynamics in Estuarine Marshes across Landscape-Scale Salinity Gradients. Ecology 89(10): 2889-2899.

de Rijk S and Troelstra SR (1997) Salt marsh foraminifera from the Great Marshes, Massachusetts: environmental controls. Palaeogeography, Palaeoclimatology, Palaeoecology 130: 81-112.

Donnelly JP and Bertness MD (2001) Rapid Shoreward Encroachment of Salt Marsh Cordgrass in Response to Accelerated Sea-Level Rise. Proceedings of the National Academy of Sciences 98(25): 14218-14223.

Donnelly JP, Cleary P, Newby P et al. (2004) Coupling instrumental and geological records of sea-level change: Evidence from southern New England of an increase in the rate of sea-level rise in the late $19^{\text {th }}$ century. Geophysical Research Letters 31: L05203. 
Edwards R and Wright A (2015) Foraminifera. In Shennan I, Long, A. J., \& Horton, B. P. (Eds.). Handbook of Sea-Level Research (pp. 452-469). Chichester, West Sussex: John Wiley \& Sons, Ltd.

Edwards RJ, Wright AJ and van de Plassche O (2004) Surface distributions of salt-marsh foraminifera from Connecticut, USA: Modern analogues for high-resolution sea level studies. Marine Micropaleontology 51: 1-21.

Engelhart SE, Horton BP, Douglas BC et al. (2009) Spatial variability of late Holocene and $20^{\text {th }}$ century sea-level rise along the Atlantic coast of the United States. Geology 37(12): 1115-1118.

Engelhart SE, Peltier WR and Horton BP (2011) Holocene relative sea-level changes and glacial isostatic adjustment of the U.S. Atlantic coast. Geology 39(8): 751-754.

Ezer T (2013) Sea level rise, spatially uneven and temporally unsteady: Why the U.S. East Coast, the global tide gauge record, and the global altimeter data show different trends. Geophysical Research Letters 40: 5439-5444.

Ezer T, Atkinson LP, Corlett WB et al. (2013) Gulf Stream's induced sea level rise and variability along the U.S. mid-Atlantic coast. Journal of Geophysical Research: Oceans 118: 685-697.

Gehrels WR (1994) Determining Relative Sea-Level Change from Salt-Marsh Foraminifera and Plant Zones on the Coast of Maine, U.S.A. Journal of Coastal Research 10(4): 990-1009.

Gehrels WR (1999) Middle and late Holocene sea-Level Changes in Eastern Maine Reconstructed from Foraminiferal Saltmarsh Stratigraphy and AMS ${ }^{14} \mathrm{C}$ Dates on Basal Peat. Quaternary Research 52: 350-359.

Gehrels WR (2000) Using foraminiferal transfer functions to produce high-resolution sea-level records from salt-marsh deposits, Maine, USA. The Holocene 10(3): 367-376.

Gehrels WR, Hayward BW, Newnham et al. (2008) A $20^{\text {th }}$ century acceleration of sealevel rise in New Zealand. Geophysical Research Letters 35: L02717.

Gehrels WR, Kirby JR, Prokoph A et al. (2005) Onset of recent rapid sea-level rise in the Western Atlantic Ocean. Quaternary Science Reviews 24: 2083-2100.

Gehrels WR and Woodworth PL (2013) When did modern rates of sea-level rise start? Global and Planetary Change 100: 263-277.

Gehrels WR and van de Plassche O (1999) The use of Jadammina macrescens (Brady) and Balticammina pseudomacrescens Brönnimann, Lutze and Whittaker 
(Protozoa: Forminiferida) as sea-level indicators. Palaeogeography, Palaeoclimatology, Palaeoecology 149:89-101.

Gerlach MJ, Engelhart SE, Kemp AC et al. (2017) Reconstructing Common Era relative sea-level change on the Gulf Coast of Florida. Marine Geology 390: 254-269.

Gordon RB and Spaulding ML (1987) Numerical Simulations of the Tidal- and WindDriven Circulation in Narragansett Bay. Estuarine, Coastal and Shelf Science 24: 611-636.

Hall GF, Hill DF, Horton BP et al. (2013) A high-resolution study of tides in the Delaware Bay: Past conditions and future scenarios. Geophysical Research Letters 40: 338-342.

Head KH (1980) Manual of Soil Laboratory Testing: Soil Classification and Compaction Tests. Pentech Press, London/Plymouth, pp. 416.

Haslett J and Parnell A (2008) A simple monotone process with application to radiocarbon-dated depth chronologies. Journal of the Royal Statistical Society, Series C, Applied Statistics 57(4): 399-418.

Horton BP (1999) The distribution of contemporary intertidal foraminifera at Cowpen Marsh, Tees Estuary, UK: Implications for studies of Holocene sea-level changes. Palaeogeography, Palaeoclimatology, Palaeoecology 149: 127-149.

Horton BP and Edwards RJ (2006) Quantifying Holocene sea-level change using intertidal foraminifera: Lessons from the British Isles. Cushman Foundation Special Publication 40: 1-97.

Horton BP, Edwards RJ and Llyod JM (1999) A Foraminiferal-Based Transfer Function: Implications for Sea-Level Studies. Journal of Foraminiferal Research 29(2): $117-129$.

Horton BP and Shennan I (2009) Compaction of Holocene strata and the implications for relative sea level change on the east coast of England. Geology 37(12): 10831086.

Hurst RW (2000) Applications of anthropogenic lead archaeo-stratigraphy (ALAS model) to hydrocarbon remediation. Environmental Forensics 1: 11-23.

Karegar MA, Dixon TH and Engelhart SE (2016) Subsidence along the Atlantic Coast of North America: Insights from GPS and late Holocene relative sea level data. Geophysical Research Letters 43: 3126-3133.

Kaufman L and Rousseeuw PJ (1990) Finding groups in Data: An introduction to Cluster Analysis. Wiley-Interscience. 
Kemp AC, Bernhardt, Horton BP et al. (2014) Late Holocene sea- and land-level change on the U.S. southeastern Atlantic coast. Marine Geology 357: 90-100.

Kemp AC, Hawkes AD, Donnelly JP et al. (2015) Relative sea-level change in Connecticut (USA) during the last 2200 yrs. Earth and Planetary Science Letters 428: 217-229.

Kemp AC, Hill TD, Vane CH et al. (2017a) Relative sea-level trends in New York City during the past 1500 years. The Holocene 1-18, DOI: $10.1177 / 0959683616683263$.

Kemp AC, Horton BP and Culver SJ (2009) Distribution of modern salt-marsh foraminifera in the Albemarle-Pamlico estuarine system of North Carolina, USA: Implications for sea-level research. Marine Micropaleontology 72(3-4): 222-238.

Kemp AC, Horton BP, Donnelly JP et al. (2011) Climate related sea-level variations over the past two millennia. Proceedings of the National Academy of Sciences 108(27): 11017-11022.

Kemp AC, Horton BP, Vane CH et al. (2013a) Sea-level change during the last 2500 years in New Jersey, USA. Quaternary Science Reviews 81: 90-104.

Kemp AC, Horton BP, Vann DR et al. (2012a) Quantitative vertical zonation of saltmarsh foraminifera for reconstructing former sea level; an example from New Jersey, USA. Quaternary Science Reviews 54: 26-39.

Kemp AC, Kegel JJ, Culver SJ et al. (2017b) Extended late Holocene relative sea-level histories for North Carolina, USA. Quaternary Science Reviews 160: 13-30.

Kemp AC, Nelson AR and Horton BP (2013b) Radiocarbon Dating of Plant Macrofossils from Tidal-Marsh Sediment. In: Shroder JF, Switzer AD and Kennedy DM (eds) Treatise on Geomorphology, Vol 14, Methods in Geomorphology. San Diego: Academic Press, pp.370-388.

Kemp AC, Sommerfield CK, Vane CH et al (2012b) Use of lead isotopes for developing chronologies in recent salt-marsh sediments. Quaternary Geochronology 12: 4049.

Kemp AC and Telford RJ (2015) Transfer functions. In: Shennan I, Long AJ and Horton BP (eds) Handbook of Sea-Level Research. Chichester, West Sussex: John Wiley \& Sons, Ltd., pp.470-499.

Kemp AC, Vane CH, Horton BP et al. (2012c). Application of stable carbon isotopes for reconstructing salt-marsh floral zones and relative sea level, New Jersey, USA. Journal of Quaternary Science, 27(4), 404-414. 
Kolker AS, Allison MA and Hameed S (2011) An evaluation of subsidence rates and sealevel variability in the northern Gulf of Mexico. Geophysical Research Letters 38(21): L21404-L21404.

Kopp RE, Kemp AC and Bittermann K (2016) Temperature-driven global sea-level variability in the Common Era. Proceedings of the National Academy of Sciences 113(11): E1434-E1441.

Kopp RE, Mitrovica JX, Griffies SM et al. (2010) The impact of Greenland melt on local sea levels: A partially coupled analysis of dynamic and static equilibrium effects in idealized water-hosing experiments. Climatic Change 103: 619-625.

Lambeck K and Chappell J (2001) Sea Level Change Through the Last Glacial Cycle. Science 292: 679-686.

Lima AL, Bergquist BA, Boyle EA et al. (2005b) High-resolution historical records from Pettaquamscutt River basin sediments: 2 . Pb isotopes reveal a potential new stratigraphic marker. Geochimica et Cosmochimica Acta 69(7): 1813-1824.

Lima AL, Hubeny JB, Reddy CM et al. (2005a) High-resolution historical records from Pettaquamscutt River basin sediments: $1 .{ }^{210} \mathrm{~Pb}$ and varve chronologies validate record of ${ }^{137} \mathrm{Cs}$ released by the Chernobyl accident. Geochimica et Cosmochimica Acta 69(7): 1803-1812.

Lin N, Kopp RE, Horton BP et al. (2016) Hurricane Sandy's flood frequency increasing from year 1800 to 2100. Proceedings of the National Academy of Sciences 113(43): 12071-12075.

Love R, Milne GA, Tarasov L et al. (2016) The contribution of glacial isostatic adjustment to projections of sea-level change along the Atlantic and Gulf coasts of North America. Earth's Future 4:440-464.

Lund DC, Lynch-Stieglitz J and Curry WB (2006) Gulf Stream density structure and transport during the last millennium. Nature 444: 601-604.

Maechler M, Rousseeuw P, Struyf A et al. (2016) Cluster: Cluster Analysis Basics and Extensions. R package version 2.0.4.

Milker Y, Nelson AR, Horton BP et al. (2016) Differences in coastal subsidence in southern Oregon (USA) during at least six prehistoric megathrust earthquakes. Quaternary Research Reviews 142: 143-163.

Mitrovica JX and Peltier WR (1991) Postglacial Geoid Subsidence Over the Equatorial Oceans. Journal of Geophysical Research 96(B12): 20,053-20,071. 
Mitrovica JX, Tamisiea ME, Davis JL et al. (2001) Recent mass balance of polar ice sheets inferred from patterns of global sea-level change. Nature 409: 1026-1029.

Neumann B, Vafeidis AT, Zimmermann J, et al. (2015) Future Coastal Population Growth and Exposure to Sea-Level Rise and Coastal Flooding - A Global Assessment. PLoS ONE 10(3): e0118571.

Niering WA and Warren RS (1980) Vegetation Patterns and Processes in New England Salt Marshes. BioScience 30(5): 301-307.

Nikitina D, Kemp AC, Engelhart SE et al. (2015) Sea-level change and subsidence in the Delaware Estuary during the last $\sim 2200$ years. Estuarine, Coastal and Shelf Science 164: 506-519.

Nixon SW (1995) Metal inputs to Narragansett Bay: A history and assessment of recent conditions. Rhode Island Sea Grant, Narragansett, Rhode Island.

Nixon SW (1982) The ecology of New England high salt marshes: A community profile. Report FWS/OBS-81/55), U.S. Fish and Wildlife Service, Washington D.C., USA.

Overpeck JT, Webb T and Prentice IC (1985) Quantitative Interpretation of Fossil Pollen Spectra: Dissimilarity Coefficients and the Method of Modern Analogs. Quaternary Research 23:87-108.

Peck JA and McMaster RL (1991) Stratigraphy and geologic History of Quaternary Sediments in Lower West Passage, Narragansett Bay, Rhode Island. Journal of Coastal Research Special Issue No. 11: 25-37.

Peltier WR (1996) Global sea level rise and glacial isostatic adjustment: an analysis of data from the east coast of North America. Geophysical Research Letters 23(7): $717-720$.

Peltier WR (2004) Global glacial isostasy and the surface of the ice-age Earth: the ICE5G (VM2) model and GRACE. Annual Review for earth and Planetary Sciencesengel 32:111-149.

Peltier WR, Argus DF and Drummond R (2015) Space geodesy constrains ice age terminal deglaciation: The global ICE-6G_C (VM5a) model. Journal of Geophysical Research: Solid Earth 120: 450-487.

Permanent Service for Mean Sea Level [PSMSL]. (2017). Obtaining Tide Gauge Data. Available from http://www.psmsl.org/data/obtaining/. 
Pfeiffer-Herbert AS, Kincaid CR, Bergondo DL et al. (2015) Dynamics of wind-driven estuarine-shelf exchange in the Narragansett Bay estuary. Continental Shelf Research 105:42-59.

Redfield CA (1965) Ontogeny of a Salt Marsh Estuary. Science 147: 50-55.

Redfield AC and Rubin M (1962) The age of salt marsh peat and its relation to recent changes in sea level at Barnstable, Massachusetts. Proceedings of the National Academy of Sciences 48(10): 1728-1735.

Reed AJ, Mann ME, Emanuel KA et al. (2015). Increased threat of tropical cyclones and coastal flooding to New York City during the anthropogenic era. Proceedings of the National Academy of Sciences 112(41): 12610-12615.

Reimer PJ, Bard E, Bayliss A et al. (2013) INTCAL13 and marine13 radiocarbon age calibration curves 0-50,000 years CAL BP. Radiocarbon 55(4): 1869-1887.

Rhode Island Department of Environmental Management [RIDEM] (2017) Overview of Climate in Rhode Island. Retrieved from http://www.dem.ri.gov/climate/climateoverview-ri.php.

Ridge JC (2003) The last deglaciation of the northeastern United States: a combined varve, paleomagnetic, and calibrated 14C chronology. Geoarcheology of Landscapes in the Glaciated Northeast. New York State Museum Bulletin 497.

Sallenger AH, Doran KS and Howd, PA (2012) Hotspot of accelerated sea-level rise on the Atlantic coast of North America. Nature Climate Change 2: 884-888.

Scott DB and Hermelin JOR (1993) A devise for precision splitting of micropaleontological samples in liquid suspension. Journal of Paleontology 67: 151-154.

Scott DS and Medioli FS (1978) Vertical zonations of marsh foraminifera as accurate indicators of former sea-levels. Nature 272: 528-531.

Sella GF, Stein S, Dixon TH et al. (2007) Observation of glacial isostatic adjustment in "stable" North America with GPS. Geophysical Research Letters 34: L02306.

Smith BN and Epstein S (1971) Two Categories of ${ }^{13} \mathrm{C} /{ }^{12} \mathrm{C}$ Ratios for Higher Plants. Plant Physiology 47(3): 380-384.

Stuiver M and Pearson GW (1993) High precision bidecadal calibration of the radiocarbon timescale, AD 1950-500 BC and 2500-6000 BC. Radiocarbon 35: 123. 
Törnqvist TE, Wallace DJ, Storms JEA et al. (2008) Mississippi Delta subsidence primarily caused by compaction of Holocene strata. Nature Geoscience 1(3): 173-176.

Tröels-Smith J (1955) Characterization of unconsolidated sediments. Geological Survey of Denmark, Series IV, No. 10.

University of Rhode Island Office of Marine Programs [URIOMP] (2017) Narragansett Bay. Retrieved from http://omp.gso.uri.edu/ompweb/doee/science/descript/baynarra.htm.

van de Plassche (1991) Late Holocene Sea-Level Fluctuations on the Shore of Connecticut Inferred from Transgressive and Regressive Overlap Boundaries in Salt-Marsh Deposits. Journal of Coastal Research 11: 159-179.

van de Plassche O (2000) North Atlantic climate-ocean variations and sea level in Long Island Sound, Connecticut since 500 cal yr A.D. Quaternary Research 53: 89-97.

van de Plassche O, van der Borg K and de Jong AFM (1998) Sea level-climate correlation during the past 1400 yr. Geology 26:319-322.

Varekamp JC, Kreulen B, Buchholtz ten Brink MR et al. (2003) Mercury contamination chronologies from Connecticut wetlands and Long Island Sound sediments. Environmental Geology 43: 268-282.

Varekamp JC and Thomas E (1998) Climate Change and the Rise and Fall of Sea Level Over the Millennium. EOS, Transactions, American Geophysical Union 79(6): 69-80.

Walton WR (1952) Techniques for recognition of living foraminifera. Contributions from Cushman Foundation for Foraminiferal Research 3: 56-60.

Watcham EP, Shennan I, and Barlow NLM (2013) Scale considerations in using diatoms as indicators of sea-level change: lessons from Alaska. Journal of Quaternary Sceince 28(2): 165-179.

Weisberg RH and Sturges W (1976) Velocity Observations in the West Passage of Narragansett Bay: A Partially Mixed Estuary. Journal of Physical Oceanography 6: 345-354.

Wigand C, McKinney RA, Charpentier, MA et al. (2003) Relationships of Nitrogen Loadings, Residential Development, and Physical Characteristics with Plant Structure in New England Salt Marshes. Estuaries 26(6): 1494-1504.

Woodworth PL, Maqueda MAM, Roussenov VM et al (2014) Mean sea-level variability along the northeast American Atlantic coast and the roles of the wind and the 
overturning circulation. Journal of Geophysical Research: Oceans 119: 89168935.

Wright AJ, Edwards RJ and van de Plassche O (2011) Reassessing transfer-function performance in sea-level reconstruction based on benthic salt-marsh foraminifera from the Atlantic coast of NE North America. Marine Micropaleontology 81(12): 43-62.

Wright AJ, Edwards RJ, van de Plassche et al (2017) Reconstructing the accumulation history of a saltmarsh sediment core: Which age-depth model is best? Quaternary Geochronology 39: 35-67.

Yin J and Goddard PB (2013) Oceanic control of sea level rise patterns along the East Coast of the United States. Geophysical Research Letters 40: 5514-5520. 